\title{
FEDERALISMO Y DERECHOS HUMANOS. EL CASO DE LA CONVENCIÓN AMERICANA SOBRE DERECHOS HUMANOS Y LA REPÚBLICA ARGENTINA
}

\author{
Ariel E. DULITZKY*
}

RESUMEN: En lo que se refiere a la garantía del cumplimiento de las disposiciones en materia de derechos humanos en el marco de la Convención Americana de Derechos Humanos, el autor plantea, tomando como punto de partida la responsabilidad de los Estados, el importante papel que juega la adecuada distribución de facultades y competencias hacia el interior de los mismos. Así, se aborda el caso argentino analizando el valor y alcance otorgados tanto a los informes de la comisión como a las sentencias de la Corte Interamericana de Derechos Humanos por parte de las cortes domésticas.

ABSTRACT: In reference to the enforcement of the human rights provisions within the framework of the American Convention on Human Rights, the author, taking state responsibility as a starting point, raises the important role played by the proper distribution of powers and competencies within the state. The author approaches the case of Argentina in this way, analyzing the significance and effect given by the domestic courts both to the reports of the Comission and to the decisions of the Interamerican Court of Human Rights.

RÉSUMÉ: En ce qui concerne la guarantie pour l'acomplissement des dispositions en matières des droit de la personne dans le cadre de la Convention Americaine des Droits de l'Hôme, l'auteur expose l'importance de la bonne distribution des roles, tout en prenant comme point de départ la responsabilités des Etats Membre. L'auteur aborde le cas Argentain tout en analisant la valeur et le pouvoir accorder aux rapports de la Comissión et aux decision de la Court Interamericaine des Droits de l'hômme par les Courts domestiques (Nationales).

* Especialista principal de la Comisión Interamericana de Derechos Humanos. Las opiniones del presente artículo son de exclusiva responsabilidad del autor y no comprometen la responsabilidad de la Comisión Interamericana de Derechos Humanos ni de la Organización de los Estados Americanos. 
SUMARIO: I. Introducción. II. La convención americana y los Estados con estructura federal. III. Reparto de competencias y derechos humanos en la jurisprudencia de la Corte Suprema de Justicia de la Nación. IV. El Estado argentino, los gobiernos provinciales y la Comisión Interamericana. V. Reflexiones

finales.

\section{INTRODUCCIÓN}

El 11 de mayo de 2005, la Corte Interamericana de Derechos Humanos (en adelante "la CIDH", "la corte" o "la corte interamericana") celebró una audiencia pública sobre las medidas provisionales conocidas como Caso de las Penitenciarías de Mendoza (Argentina). ${ }^{1}$ En la audiencia se discutió la situación de seguridad de las personas privadas de la libertad en la Penitenciaría Provincial de Mendoza y en la unidad penitenciaria Gustavo André, de Lavalle, ambas en la Provincia de Mendoza en Argentina. ${ }^{2}$

El tratamiento por parte del sistema interamericano de derechos humanos de lo que sucede con personas privadas de su libertad por autoridades provinciales, permite una reflexión sobre la relación entre federalismo y protección internacional de los derechos humanos. Los periódicos locales mendocinos entendieron que la provincia y no el Estado argentino estaba siendo juzgada ante el tribunal interamericano. ${ }^{3}$ Es esta una representación adecuada de la práctica internacional? Quién es el obligado a dar cumplimiento a las obligaciones internacionales? El Estado nacional como ratificante de los distintos instrumentos internacionales

1 Véase Corte IDH, Comunicado de Prensa, CIDH-Cp-04/05.

2 Idem y véase Corte IDH, Resolución de la Corte Interamericana de Derechos Humanos, de 22 de noviembre de 2004, Solicitud de Medidas Provisionales Presentada por la Comisión Interamericana de Derechos Humanos, respecto de la República de Argentina, Caso de las Penitenciarías de Mendoza. En su solicitud de adopción de medidas provisionales, la Comisión Interamericana de Derechos Humanos describió que en dichos centros penitenciarios, han resultado muertas o heridas varias personas privadas de libertad, así como guardias penitenciarios. Estos hechos han ocurrido durante un período de siete meses, en incendios, peleas entre internos, así como en circunstancias que no han sido esclarecidas. La comisión alegó que las condiciones de seguridad, infraestructura, hacinamiento, detención y salubridad que actualmente prevalecen en estas cárceles podrían provocar otros incidentes, así como nuevos homicidios y actos de violencia. Véase resolución citada.

3 Véase, Mendoza defiende en Paraguay su política carcelaria, Periódico Los Andes, 11 de mayo, http://www.losandes.com.ar/nota.asp? $n r c=251014$, visitado por última vez el 23 de mayo de 2005. 
o el estado provincial en tanto que la competencia en materia de condiciones de detención cae bajo su órbita jurisdiccional? Puede el Estado nacional obligar a las provincias a cumplir con obligaciones internacionales que están bajo la esfera local de distribución de competencias? Es posible que una provincia viole una norma internacional de derechos humanos a pesar de que no es parte del tratado? Qué sucede si el Estado federal carece de facultades para hacer cumplir a las provincias con las obligaciones internacionales?

En definitiva, estas y otras cuestiones similares demuestran que la estructura federal de diversos Estados de nuestro continente repercute interna e internacionalmente a la hora de dar cumplimiento a las obligaciones emergentes de las normas internacionales de derechos humanos. En muchas ocasiones los agentes públicos responsables de violaciones a los derechos humanos dependen de los gobiernos locales y no del federal. El gobierno federal puede encontrarse en la situación embarazosa de tener que responder a denuncias internacionales por faltas cometidas por sus Estados federados que las autoridades centrales no comparten y de hecho condenan. ${ }^{4}$

También resulta cierto que varios países han intentado ampararse en su estructura federal para limitar los efectos internos de la ratificación de tratados de derechos humanos o para restringir el alcance de su responsabilidad internacional. Paralelamente, autoridades locales han pretendido desatenderse de las obligaciones que les corresponden argumentando que los tratados han sido ratificados por el gobierno federal y no por el estadual y por ende no deben cumplir con los mismos.

4 Konder Comparato, Fabio, "A proteçao a os direitos humanos e a organizaçao federal de competências", en varios autores, A Incorporaçao das normas internacionais de proteçao dos direitos humanos no direito brasilero, 1996, p. 281. En adelante, A Incorporaçao. Un ejemplo categórico de esta situación se produjo en el caso Toomen contra Australia ante el Comité de Derechos Humanos de Naciones Unidas. En dicho caso se cuestionaba dos disposiciones del Código Penal de Tasmania que tipificaban como delitos diversas formas de contacto sexual entre hombres, incluida cualquier forma de contacto sexual entre hombres homosexuales adultos, con su consentimiento y en privado. El gobierno federal australiano concordó con el señor Toomen en que éste último había sido víctima de injerencia arbitraria en su vida privada e incluso que podría ser víctima de discriminación y claramente indicó que no compartía los razonamientos de las autoridades de Tasmania. En su respuesta al Comité de Derechos Humanos, el gobierno australiano acompañó las defensas producidas por el gobierno de Tasmania. Véase Comité de Derechos Humanos, Nicholas Toonen v. Australia, Comunicación núm. 488/1992, U.N.Doc. CCPR/C/50/D/488/1992 (1994), en particular párrafos 6.1 y ss. 
Por supuesto que no puede excluirse que existan circunstancias en las que la estructura federal permite que la protección de los derechos humanos sea mayor o mejor a nivel local que a nivel federal..$^{5}$ Por ejemplo, es posible que las Constituciones y leyes estaduales contengan mayores protecciones o reconozcan más derechos que sus pares federales. ${ }^{6}$ También es factible que las normas jurídicas o instituciones destinadas a la protección de los derechos emerjan primariamente a nivel estadual para luego consolidarse federalmente. ${ }^{7}$ Además, el federalismo ofrece la posibilidad teórica de un doble nivel de protección de los derechos a través de los mecanismos judiciales de los estados federados y de la Federación. ${ }^{8}$

Las potencialidades y dificultades que ofrece el federalismo obligan a definir el alcance de las obligaciones internacionales de un Estado con estructura federal. Ello, a fin de no restringir o limitar indebidamente la protección internacional para los habitantes de Estados con estructura federal así como para evitar que el derecho internacional y en particular los órganos internacionales condicionen o impidan el armónico funcionamiento de la distribución de los poderes hacia el interior de las federaciones.

En el caso de Argentina, múltiples de los problemas, estructurales o coyunturales relativos a la vigencia, respeto y garantía de los derechos se producen concurrente o exclusivamente a nivel provincial. ${ }^{9}$

5 Véase por ejemplo, Brennan, William Jr., "State Constitutions and the Protection of Individual Rights", 90 Harv. L. Rev. 489 (1977) (argumentando que las Constituciones estatales son fuente de derechos que muchas veces van más allá que la Constitución federal y por ende los tribunales estatales no están limitadas al interpretar las Constituciones estatales por la interpretación de la corte suprema de justicia a la Constitución federal) y Howard, Dick, "Protecting Human Rights in a Federal System", en Tushnet Mark (ed.), Comparative Constitutional Federalism, Europe and America, 1990, p. 114 (sosteniendo que los Estados pueden proteger más ampliamente los derechos).

6 Por ejemplo, el artículo 18 de la Constitución de la Provincia de Tierra del Fuego en Argentina reconoce toda una serie de derechos a los niños que no tienen una recepción expresa en la Constitución Argentina, salvo la jerarquización constitucional de la Convención sobre los Derechos del Niño y una mención sobre acciones afirmativas a favor de la niñez en el artículo 75 inciso 24.

7 Por ejemplo en Canadá, la Carta de Derechos y Libertades de la Persona de Québec fue adoptada en 1975 mientras que la Carta Canadiense de Derechos y Libertades fue adoptada en 1982. En México, la Procuraduría de Protección Ciudadana del estado de Aguascalientes fue creada en 1988 mientras que la Comisión Nacional de Derechos Humanos fue creada por decreto presidencial en 1990 y elevada a rango constitucional sólo en 1992.

8 Véase Woehrling, José, "Convergences et divergentes entre fédéralisme et protection des droits et libertés: 1'exemple des Etats-Unis et du Canada", (2000) 46 R.D.McGill 21, pp. 39 y ss.

9 Véase por ejemplo, Sued, Gabriel, "Los poderes judiciales provinciales, amenazados", $L a$ Naciónline, lunes 18 de abril de 2005 (describiendo problemas de la independencia de los poderes 
Por eso no sorprende que en los últimos cinco años los órganos del sistema interamericano, hayan debido prestar especial atención a esta situación ya sea a través de casos individuales o visitas a Argentina. ${ }^{10}$

La Comisión Interamericana de Derechos Humanos realizó varias visitas de trabajo al país para analizar la situación de los derechos humanos en distintas provincias argentinas o para tratar casos concretos relativos a dichas provincias.

judiciales de las provincias) visitado por última vez 4 de junio de 2005. Esta situación no es exclusiva ni particular de Argentina. Solamente para dar ejemplos puede citarse CIDH, Informe sobre Situación de los Derechos de la Mujer en Ciudad Juárez, México: El Derecho a no ser Objeto de Violencia y Discriminación OEA/Ser.L/V/II.117, Doc. 1 rev. 1, 7 marzo 2003, original: español (dando cuenta de la situación en el Estado de Chihuahua en México) o CIDH, Informe sobre la Situación de los Derechos Humanos en Venezuela OEA/Ser.L/V/II.118, Doc. 4 rev. 1, 24 octubre 2003, original: español, el capítulo IV (dando cuenta de la existencia de grupos parapoliciales en siete estados venezolanos).

10 Esta situación no es exclusiva de Argentina. Con respecto a México y la adopción de informes de la CIDH con relación hechos ocurridos en los estados de la unión, puede verse, además del ya citado Informe sobre la Situación de los Derechos de La Mujer en Ciudad Juárez, México: El Derecho a no ser Objeto de Violencia y Discriminación, los siguientes informes: Informe núm. 67/04, Petición 938/03, Admisibilidad, Alejandro Junco De La Vega y Eugenio Herrera Terrazas, México, 14 de octubre de 2004 (se cuestiona la Ley de Instituciones Políticas y Procesos Electorales del Estado de Coahuila); Informe núm. 9/03, Petición 12.116, Admisibilidad, María Estela García Ramírez y Celerino Jiménez Almaraz, México, 20 de febrero de 2003 (se refiere a la presunta detención ilegal, tortura, y ejecución extrajudicial de Celerino Jiménez Almaraz por parte de la Policía Judicial del Estado de Oaxaca; el hostigamiento y amenazas a su esposa María Estela García Ramírez; y la falta de investigación y sanción a los responsables de tales hechos); Informe núm. 10 103, Petición 12.185, Admisibilidad, Tomás De Jesús Barranco, México, 20 de febrero de 2003, (se alega la presunta detención ilegal, tortura física y psicológica a Tomás de Jesús Barranco, así como su posterior condena a cuarenta años de prisión y el pago de cincuenta y cinco mil seiscientos veintiséis pesos por los delitos de terrorismo y homicidio en el Estado de Guerrero); Informe núm. 81/03, Petición12.287, Admisibilidad, Cruz Ávila Mondragón, México, 22 de octubre de 2003 (se denuncia la privación arbitraria de libertad, tortura y desaparición forzada de Cruz Ávila Mondragón en Chihuahua); Informe núm. 69/03, Petición 11.807, Solución Amistosa, José Alberto Guadarrama García, México, 10 de octubre de 2003 (acuerdo de solución amistosa por hechos ocurridos en el Estado de Morelos). Existen diversos artículos que describen varios de los casos relativos a México ante los órganos del sistema interamericano de derechos humanos. Véase por ejemplo, Carmona Tinoco, Jorge Ulises, "Algunos aspectos de la participación de México ante los órganos del sistema interamericano de protección de los derechos humanos", Cuestiones Constitucionales, Revista Mexicana de Derecho Constitucional, México, UNAM, Instituto de Investigaciones Jurídicas, núm. 9, julio-diciembre de 2003, pp. 3-54; Peraza Parga, Luis, "México y el sistema interamericano de protección de los derechos humanos", en Méndez Silva, Ricardo (coord.), Derecho internacional de los derechos humanos, Memoria del VII Congreso Iberoamericano de Derecho Constitucional, México, 2002, pp. 645 y ss.; y Corcuera C., Santiago y Guevara B., José A., México ante el sistema interamericano de protección de los derechos humanos, México, Comisión de Derechos Humanos del Distrito Federal-Universidad Iberoamericana, 2003. 
Así en 2002, la CIDH visitó Neuquén, Río Negro y Salta, ${ }^{11}$ en 2003, la comisión visitó Santiago del Estero ${ }^{12}$ y en 2004 realizó una visita a Mendoza. Asimismo, la comisión ha tenido que considerar múltiples casos relativos a actuaciones de distintas autoridades provinciales. En los últimos años, la CIDH ha declarado admisibles casos relativos a acciones $\mathrm{u}$ omisiones de agentes de las provincias de Santa Fe, ${ }^{13}$ Buenos Aires, ${ }^{14}$ Chaco ${ }^{15}$ y Mendoza. ${ }^{16}$ La CIDH también publicó un acuerdo de solución amistosa en un caso cuyos hechos ocurrieron en la Provincia del Chaco. ${ }^{17}$

La Corte Interamericana de Derechos Humanos también ha tenido oportunidad de resolver casos que ocurrieron o tuvieron su origen en alguna provincia. El tribunal ha decidido un caso relativo a las acciones y omisiones de las autoridades de Mendoza y otro que tuvo su origen en la Provincia de Santiago del Estero. ${ }^{18}$ Como hemos dicho al inicio, la corte

11 Véase Comunicado de Prensa núm. 33-02, comisión interamericana concluye visita a la República Argentina.

12 Véase Comunicado de Prensa núm. 23-03, Visita de Trabajo de la CIDH a la República Argentina.

13 CIDH, Informe núm. 4/04, Petición 12.324, Admisibilidad, Rubén Luis Godoy, Argentina, 24 de febrero de 2004; Informe núm. 2/03, Admisibilidad, Petición 11.306, José Eduardo Acurso, Argentina, 20 de febrero de 2003.

14 CIDH, Informe núm.1/03, Petición 12.221, Admisibilidad, Jorge Omar Gutiérrez, Argentina, 20 de febrero de 2003; Informe núm. 51/03; Petición 11.819, Admisibilidad, Christian Daniel Domínguez Domenichetti, Argentina, 24 de octubre de 2003; Informe núm. 72/03, Petición 12.159; Admisibilidad, Gabriel Egisto Santillan, Argentina, 22 de octubre 2003; Informe núm. 5/02, Admisibilidad, Petición 12.080, Sergio Schiavini y María Teresa Schnack de Schiavini, Argentina, 27 de febrero de 2002.

15 CIDH, Informe núm. 72/01, Caso 11.804, Juan Ángel Greco, Argentina, 10 de octubre de 2001 Informe núm. 91/03.

16 CIDH, Informe núm. 91/00, Caso 11.796, Mario Gómez Yardez, Argentina, 10 de octubre de 2000 .

17 Informe núm. 91/03, Petición 11.804, Solución Amistosa, Juan Ángel Greco, Argentina, 22 de octubre de 2003 (en el caso se denunciaba la detención ilegal así como el mal trato recibido en la Comisaría de de Puerto Vilelas, Provincia del Chaco, en la que ocurrió un incendio cuyas quemaduras le provocaron finalmente la muerte al señor Greco).

18 Corte IDH, Caso Garrido y Baigorria. Reparaciones (artículo 63.1 Convención Americana sobre Derechos Humanos). Sentencia de 27 de agosto de 1998. Serie C No. 39 y Corte IDH, Caso Cantos. Sentencia de 28 de noviembre de 2002. Serie C No. 97. Debe aclararse que en el caso Cantos, dada su competencia temporal, la corte solamente se refirió a las actuaciones judiciales ante la Corte Suprema de Justicia de la Nación y no a los hechos ocurridos en la Provincia de Santiago del Estaero. Véase Corte IDH, caso Cantos, Excepciones Preliminares, Sentencia de 7 de septiembre de 2001. 
ha adoptado medidas provisionales con relación a la situación en las penitenciarías de la Provincia de Mendoza. ${ }^{19}$

A poco más de una década de la profunda reforma de 1994 a la Constitución de la Nación Argentina vale la pena por ende reflexionar sobre algunas de las implicaciones de la jerarquía constitucional otorgada a los instrumentos de derechos humanos mencionados en el artículo 75 inciso 22 de la Constitución ${ }^{20}$ y en particular de la convención americana en el aspecto relativo a la estructura federal del país. Dado que los instrumentos incluidos en el artículo 75 inciso 22, tienen jerarquía constitucional "en las condiciones de su vigencia" debe analizarse cuáles son dichas condiciones en el ámbito de las provincias y en particular cuáles son las obligaciones que surgen para el gobierno federal y para las autoridades provinciales respectivas. ${ }^{21}$

19 Corte IDH, Resolución de la Corte Interamericana de Derechos Humanos, de 22 de noviembre de 2004, Solicitud de Medidas Provisionales Presentada por la Comisión Interamericana de Derechos Humanos, respecto de la República de Argentina, Caso de las Penitenciarías de Mendoza.

20 Véase artículo 75 inciso 22: Aprobar o desechar tratados concluidos con las demás naciones y con las organizaciones internacionales y los concordatos con la Santa Sede. Los tratados y concordatos tienen jerarquía superior a las leyes. La Declaración Americana de los Derechos y Deberes del Hombre; la Declaración Universal de Derechos Humanos; la Convención Americana sobre Derechos Humanos; el Pacto Internacional de Derechos Económicos, Sociales y Culturales; el Pacto Internacional de Derechos Civiles y Políticos y su Protocolo Facultativo; la Convención sobre la Prevención y la Sanción del Delito de Genocidio; la Convención Internacional sobre la Eliminación de todas las Formas de Discriminación Racial; la Convención sobre la Eliminación de todas las Formas de Discriminación contra la Mujer; la Convención contra la Tortura y otros Tratos o Penas Crueles, Inhumanos o Degradantes; la Convención sobre los Derechos del Niño: en las condiciones de su vigencia, tienen jerarquía constitucional, no derogan artículo alguno de la primera parte de esta Constitución y deben entenderse complementarios de los derechos y garantías por ella reconocidos. Sólo podrán ser denunciados, en su caso, por el Poder Ejecutivo nacional, previa aprobación de las dos terceras partes de la totalidad de los miembros de cada cámara. Los demás tratados y convenciones sobre derechos humanos, luego de ser aprobados por el congreso, requerirán del voto de las dos terceras partes de la totalidad de los miembros de cada cámara para gozar de la jerarquía constitucional.

21 La Corte Suprema de Justicia de la Nación argentina ha dicho que el término "en las condiciones de su vigencia" significa "tal como la Convención... efectivamente rige en el ámbito internacional y considerando particularmente su efectiva aplicación jurisprudencial por los tribunales internacionales competentes para su interpretación y aplicación. De ahí que la jurisprudencia de la corte interamericana deba servir de guía para la interpretación de los preceptos convencionales" CSJN, Caso Giroldi Fallos 318-514, párr. 11. La corte suprema también indicó en otro caso que "la opinión de la Comisión Interamericana de Derechos Humanos debe servir de guía para la interpretación de los preceptos convencionales" CSJN, Caso Bramajo, Fallos 318:240. No consideraremos en este trabajo, los desarrollos jurisprudenciales posteriores de la corte suprema, en el que si bien no desconoció el valor de pauta de interpretación a los pronunciamientos de la Comisión Interamericana de Derechos Humanos, sí les restó fuerza obligatoria o vinculante para los 
En el presente artículo realizaremos en primer lugar un análisis de las obligaciones y responsabilidades de un estado federal de acuerdo a la normativa de la convención americana. En las siguientes secciones analizaremos específicamente la regulación y la interpretación de la convención americana en materia de Estados con estructura federal. El análisis partirá de un estudio de las obligaciones generales que tienen todos los Estados partes, es decir las de respeto y garantía de los derechos humanos y las deber de adoptar normas de derecho interno en conjunción con la cláusula federal y las particularidades en los Estados federales. Dado que una característica de los Estados federales es el reparto de competencias entre el gobierno central y los gobiernos locales, también exploraremos dos temas relacionados. Por un lado, la disparidad de regulaciones en materia de derechos humanos al interior de un Estado federal y el principio de no discriminación. Por el otro, un análisis de este reparto de competencias a la luz de la cláusula federal de la Convención. Esta sección concluye con un esbozo de las obligaciones que las unidades integrantes de la Federación tienen con relación a la convención americana.

En la siguiente parte del artículo estudiaremos la jurisprudencia de la Corte Suprema de Justicia de la nación argentina en materia de reparto de competencias entre el gobierno nacional y los gobiernos provinciales en cuanto a la obligación de cumplir con los tratados de derechos humanos. En particular, las obligaciones que la jurisprudencia argentina ha impuesto a los gobiernos provinciales en cuanto al respeto y garantía de los derechos reconocidos internacionalmente.

La situación que describimos anteriormente en cuanto a la intervención que los órganos del sistema interamericano han tenido con relación a violaciones ocurridas en el ámbito provincial nos ha llevado a incluir una sección final donde se analizan principalmente dos casos que han concluido satisfactoriamente con acuerdos de solución amistosa ante la comisión interamericana.

El artículo concluye con unas breves reflexiones finales, destinadas principalmente a llamar la atención sobre la necesidad de crear un mecanismo que provea el espacio institucional y las herramientas jurídicas necesarias para coordinar las actividades entre el gobierno nacional y los

jueces de la nación. Véase CSJN Acosta, Fallos 321:3555 y Felicetti, Fallos 323:4130. Por lo tanto, en este artículo analizaremos especialmente los alcances de la convención americana en un Estado federal como la Argentina, particular pero no exclusivamente a la luz de la jurisprudencia de la corte interamericana y de la práctica de la comisión. 
gobiernos provinciales tanto de manera preventiva y proactiva para facilitar el respeto y garantía de los derechos humanos tanto a nivel federal como local.

\section{LA CONVENCIÓN AMERICANA Y LOS ESTADOS CON ESTRUCTURA FEDERAL}

Resulta útil recordar el artículo 28 de la convención:

Artículo 28. Cláusula Federal

1. Cuando se trate de un Estado parte constituido como Estado Federal, el gobierno nacional de dicho Estado parte cumplirá todas las disposiciones de la presente Convención relacionadas con las materias sobre las que ejerce jurisdicción legislativa y judicial.

2. Con respecto a las disposiciones relativas a las materias que corresponden a la jurisdicción de las entidades componentes de la Federación, el gobierno nacional debe tomar de inmediato las medidas pertinentes, conforme a su constitución y sus leyes, a fin de que las autoridades competentes de dichas entidades puedan adoptar las disposiciones del caso para el cumplimiento de esta Convención.

3. Cuando dos o más Estados partes acuerden integrar entre sí una Federación u otra clase de asociación, cuidarán de que el pacto comunitario correspondiente contenga las disposiciones necesarias para que continúen haciéndose efectivas en el nuevo Estado así organizado, las normas de la presente Convención.

Esta cláusula federal tiene en mente en sus primeros dos incisos solamente a un grupo de Estados, aquellos con estructura federal frente a la gran mayoría del resto del articulado convencional que se dirige sin distinción a la totalidad de los Estados parte. ${ }^{22} \mathrm{~A}$ fin de analizar las obligaciones que emergen de la convención americana en los Estados federales

22 Carnota, Walter, Federalismo y derechos humanos, E. D., pp. 127-911. Otros artículos que podrían tener estas características son el 4 inciso 2 que se dirige solamente a aquellos Estados que mantienen la pena de muerte (estableciendo los requisitos para su imposición); el 5 inciso 5 que se refiere solamente a los Estados que permiten el procesamiento de menores de edad (requiriendo que sean separados de los adultos y llevados ante tribunales especializados, con la mayor celeridad posible, para su tratamiento); el 6 inciso 2 que se refiere a los países donde ciertos delitos tengan señalada pena privativa de la libertad acompañada de trabajos forzosos o el 6 inciso 3.b. que se indica que "en los países donde se admite exención por razones de conciencia [al servicio militar], el servicio nacional que la ley establezca en lugar de aquél". 
es indispensable leer conjunta e integralmente todo el texto convencional y no de manera aislada su cláusula federal. En particular deben considerarse los artículos 1 y 2 convencionales. El artículo 1 inciso 1 indica:

1. Los Estados partes en esta Convención se comprometen a respetar los derechos y libertades reconocidos en ella y a garantizar su libre y pleno ejercicio a toda persona que esté sujeta a su jurisdicción, sin discriminación alguna por motivos de raza, color, sexo, idioma, religión, opiniones políticas o de cualquier otra índole, origen nacional o social, posición económica, nacimiento o cualquier otra condición social.

\section{Por su parte el artículo 2 señala que:}

Si en el ejercicio de los derechos y libertades mencionados en el artículo 1 no estuviere ya garantizado por disposiciones legislativas o de otro carácter, los Estados partes se comprometen a adoptar, con arreglo a sus procedimientos constitucionales y a las disposiciones de esta Convención, las medidas legislativas o de otro carácter que fueren necesarias para hacer efectivos tales derechos y libertades.

Una lectura armónica e integral de estas disposiciones, permite sostener que la convención americana establece como deberes fundamentales a cargo de los Estados parte, es decir, los Estados con estructura federal, unitaria o cualquier otra, los de respeto y garantía del pleno ejercicio de los derechos humanos en ella reconocidos (artículo 1.1). Adicionalmente coloca a los Estados parte con organización federal en la obligación de adoptar las disposiciones de derecho interno pertinentes y necesarias para cumplir con tales deberes (artículos 2 y 28.2).

Las dos obligaciones generales consagradas en la convención americana: la de respetar y garantizar los derechos protegidos (artículo 1.1) y la de adecuar el derecho interno a la normativa internacional (artículo 2) se hallan indisolublemente interrelacionadas y no condicionadas por el artículo 28. La cláusula federal precisa el alcance de las obligaciones generales pero no las limita. ${ }^{23}$

23 En un caso aislado, la corte interamericana interpretó erróneamente que el artículo 28 de la convención prevé la hipótesis de que un Estado federal, en el cual la competencia en materia de derechos humanos corresponde a los Estados federados, quiera ser parte en ella. Corte IDH, Caso Garrido y Baigorria. Reparaciones (artículo 63.1 Convención Americana sobre Derechos Humanos). Sentencia de 27 de agosto de 1998. Serie C No. 39, párr. 46. Es decir a un supuesto previo a la 
Una interpretación del artículo 28, aislada del resto de la convención y de los principios generales del derecho, "conduciría a relevar al gobierno central de sus obligaciones bajo la convención y podría dejar a las personas privadas de protección internacional". ${ }^{24}$ Jamás, siguiendo las reglas de interpretación establecidas en el artículo 31 de la Convención de Viena sobre Derecho de los Tratados y en especial el artículo 29, inciso a de la convención americana, se podría concluir que el artículo 28 restringe los deberes del Estado federal. Como dice el artículo 29.a: "Ninguna disposición de la presente convención, puede ser interpretada en el sentido de permitir a alguno de los Estados partes... suprimir el goce y ejercicio de los derechos y libertades reconocidos en la Convención".

Del artículo 1 de la convención se desprende que el Estado tiene dos obligaciones básicas: respetar y garantizar los derechos reconocidos $a$ toda persona que esté sujeta a su jurisdicción. Por lo tanto, en los términos del derecho internacional, es claro que en los Estados federales, las personas están sujetas a su jurisdicción independientemente de que se encuentren o residan en los ámbitos provinciales o federales. ${ }^{25}$

ratificación y no como tema de implementación interna del tratado o de generación de responsabilidad. Seguramente la corte en el caso se vio influenciada por la opinión del juez ad hoc, designado por Argentina, Julio Barberis, que sostiene esta posición. Véase, Barberis, Consideraciones, p. 249. Esta interpretación del tribunal, no se compadece que los precedentes interamericanos que hemos reseñado, tampoco con el claro texto del artículo 28 que habla de Estado parte en su inciso 1, lo que significa que ese está en el supuesto de un Estado que ya ha ratificado. Además, el mismo inciso 1 menciona que el gobierno federal cumplirá todas las obligaciones sobre las que tenga competencia, es decir una obligación de futuro y no previa a la ratificación. Por último, el artículo 28 se ubica en el capítulo IV de la convención, relativo a la suspensión de garantías, interpretación y aplicación del tratado, es decir claramente el supuesto de la convención ya vigente luego de su ratificación y cuando debe ser implementada por el Estado parte. el capítulo X regula lo relativo a firma, ratificación, reserva, enmienda, protocolo y denuncia de la convención. Específicamente el artículo 74 en sus dos incisos se refiere a las firmas y ratificaciones y el artículo 75 a reservas. La interpretación de la corte sería en su caso una reserva a la aplicación de la convención en un Estado federal o en todo caso una interpretación declarativa acerca de cómo el Estado distribuiría internamente las competencias para cumplir con el tratado. De hecho, la propia corte de manera contradictoria con su mención previa, agrega en el mismo párrafo que dado que desde el momento de la aprobación y de la ratificación de la convención la Argentina se comportó como si dicha competencia en materia de derechos humanos correspondiera al Estado federal, no puede ahora alegar lo contrario pues ello implicaría violar la regla del estoppel. Corte IDH, Caso Garrido y Baigorria. Reparaciones (artículo 63.1 Convención Americana sobre Derechos Humanos). Sentencia de 27 de agosto de 1998. Serie C No. 39, párr. 46. En otras palabras, la corte analiza la actuación del Estado argentino con relación al artículo 28 en las etapas tanto anterior como posterior a la ratificación.

24 CIDH, Informe núm. 8/91, Caso 10.180, México, 22 de febrero de 1991, párr. 41.

25 Con dicho alcance la referencia al concepto de jurisdicción en el artículo 28 incisos 1 y 2 se puede considerar un error de técnica legislativa y que pareciera más apropiado hablar de competencia. Pero además, el artículo 28 en ambos incisos hace mención a la jurisdicción legislativa 
El sistema de la convención está dirigido a reconocer derechos y libertades a las personas y no a facultar a los Estados a hacerlo. El hecho de que los Estados puedan fijar las condiciones del ejercicio de un derecho determinado, no impide su exigibilidad conforme al derecho internacional. En consecuencia, si por cualquier circunstancia, incluida la estructura federal del Estado, el derecho no pudiera ser ejercido por "toda persona" sujeta a la jurisdicción de un Estado, ello constituiría una violación de la convención susceptible de ser denunciada ante los órganos de protección previstos en ella. ${ }^{26} \mathrm{El}$ artículo 1 de la convención no distingue entre personas sujetas a la jurisdicción de Estados federales y personas sujetas a la jurisdicción de Estados unitarios. Contiene una norma de carácter general que se extiende a todas las disposiciones del tratado incluido el artículo 28.

El artículo 1 de la convención obliga a los Estados parte no solamente a respetar los derechos y libertades reconocidos en ella, sino a garantizar su libre y pleno ejercicio a toda persona sujeta a su jurisdicción. La corte ha dicho que esta disposición contiene un deber positivo para los Estados, consistente en la obligación del Estado de tomar todas las medidas necesarias para remover los obstáculos que puedan existir para que los individuos puedan disfrutar de los derechos que la convención reconoce. ${ }^{27} \mathrm{La}$ estructura federal del Estado puede constituirse en uno de dichos obstáculos para el efectivo goce de los derechos y por ende, el gobierno central deberá efectuar y adoptar todas las medidas necesarias para evitar que la estructura federal impida o dificulte dicho goce. Ello no implica eliminar el federalismo sino lograr que el gobierno central y los gobiernos locales se encuentren en condiciones de asegurar el efectivo disfrute de los derechos.

El deber de garantía contiene diversas obligaciones puntuales, siendo la primera de ellas el de la prevención que:

Abarca todas aquellas medidas de carácter jurídico, político, administrativo y cultural que promuevan la salvaguarda de los derechos humanos y

y judicial dejando por fuera la ejecutiva o administrativa que es de suma importancia y crucial ya que la responsabilidad del Estado no se genera exclusivamente por la acción u omisión de sus poderes legislativos y judicial.

26 Véase mutatis mutandi, Corte IDH, Exigibilidad del Derecho de Rectificación o Respuesta, Opinión consultiva OC- 7/86, de 29 de agosto de 1986, párr. 24.

27 Corte IDH, Excepciones al agotamiento de los Recursos Internos, Opinión Consultiva OC 11/90 del 10 de agosto de 1990, párr. 34. 
que aseguren que las eventuales violaciones a los mismos sean efectivamente consideradas y tratadas como un hecho ilícito que, como tal, es susceptible de acarrear sanciones para quien las cometa, así como la obligación de indemnizar a las víctimas por sus consecuencias perjudiciales. ${ }^{28}$

La corte evitó hacer una enumeración detallada de esas medidas ya que las mismas varían según el derecho de que se trate y según las condiciones propias de cada Estado parte. ${ }^{29}$ Indudablemente, la estructura federal del Estado parte obligará a adaptar el tipo de medidas en función precisamente de esta estructura y de la distribución de competencias entre la Federación y sus unidades componentes. Pero no relevará al Estado de adoptar por sí o a través de sus unidades territoriales las medidas necesarias para asegurar que los derechos reconocidos en la convención sean efectivamente respetados o para prevenir sus violaciones.

El deber de garantía también exige que el Estado directamente o por medio de las autoridades locales competentes investigue toda violación a los derechos humanos y sancione a los responsables..$^{30}$ Esta obligación, en muchas circunstancias puede resultar de difícil cumplimiento especialmente cuando violaciones cometidas por agentes provinciales deben ser investigadas y juzgadas por los órganos de procuración y administración de justicia provinciales. La frecuente falta de voluntad o capacidad para llevar a cabo dichas investigaciones y juzgamientos a nivel local, estadual o provincial ha concitado mucha atención en Estados con estructura federal. ${ }^{31}$ En varios países precisamente para dotar al gobierno fede-

28 Caso Corte IDH Velásquez Rodríguez, párr. 174.

29 Idem.

30 Corte IDH, Caso de las Hermanas Serrano Cruz. Sentencia de 1 de marzo de 2005. Serie C No. 120, párr. 64 .

31 En los Estados Unidos, el gobierno federal ha adoptado legislación a nivel federal tanto en el área civil como la penal para buscar remedios judiciales por violaciones a los derechos constitucionales o civiles. Múltiples leyes federales han establecido garantías a nivel federal en materia de derechos civiles con lo cual es el gobierno federal el que adquiere competencia para realizar su implementación, incluida su investigación y juzgamiento por tribunales civiles. Véase por ejemplo, Civil Rights Acts, Voting Rights Act, Equal Credit Opportunity Act; Americans with Disabilities Act; National Voter Registration Act; Uniformed and Overseas Citizens Absentee Voting Act; Voting Accessibility for the Elderly and Handicapped Act; Civil Rights of Institutionalized Persons Act; Freedom of Access to Clinic Entrances Act; Police Misconduct Provision of the Violent Crime Control and Law Enforcement Act; Immigration Reform and Control Act; Immigration and Nationality Act y El Violent Crime Control and Law Enforcement Act de 1994. La Corte Suprema de los Estados Unidos ha sostenido la constitucionalidad de la posibilidad de que la jurisdicción federal juzgue estos hechos. Véase por ejemplo, 383 US 745, United States v. Guest (1968). Debe tenerse en cuenta de todas maneras que en los Estados Unidos, ninguna de las disposiciones 
ral con mayores herramientas se ha dado una tendencia de federalizar la persecución de los delitos vinculados a la violación de derechos humanos. Así en Brasil una reciente reforma constitucional establece que:

Artículo 109: Corresponde a los jueces federales:

V. A las causas relativas a derechos humanos a que se refiere el $\S 50$. de este artículo; § 5o. En las hipótesis de graves violaciones a los derechos humanos, el Procurador General de la República, con la finalidad de asegurar el cumplimiento de las obligaciones emergentes de tratados internacionales de derechos humanos de los que Brasil sea parte, podrá suscitar, ante el Superior Tribunal de Justicia, en cualquier fase de la investigación o del proceso, incidente de transferencia de competencia para la Justicia Federal. ${ }^{32}$

En el mismo sentido, en México existen diversas iniciativas de reforma constitucional con el objetivo de otorgar competencia a la justicia federal en materia de violaciones a los derechos humanos. Por ejemplo, el presidente Vicente Fox ha propuesto adicionar a la Constitución lo siguiente: "Asimismo, las autoridades federales podrán conocer de los delitos del fuero común relacionados con violaciones a los derechos humanos, cuando estas trasciendan el ámbito de los estados o del Distrito Federal, en los términos que establezca la ley". ${ }^{33}$

Del deber de garantía también se desprende la obligación de reparar el daño que haya sido causado por una eventual violación a alguno de los derechos reconocidos. El Estado no puede invocar disposiciones de derecho interno para modificar o incumplir la obligación de reparar ya que está sujeta en todos los aspectos (alcance, naturaleza, modalidades y determinación de los beneficiarios) al derecho internacional. ${ }^{34}$ De modo,

mencionadas precedentemente han sido adoptadas con el objetivo de dar cumplimiento a las obligaciones de los pocos tratados de derechos humanos ratificados por dicho país. Por el contrario, es bastante claro que la ratificación de las convenciones de derechos humanos, no tiene por objeto federalizar materias que pudiesen corresponder a los Estados de la unión.

32 Emenda Constitucional núm. 45/2004, Publicada no DOU de 31/12/2004 (traducción propia). Véase Piovesan, Flavio, Reforma do Judiciario e Direitos Humanos, mimeo, s. f., pp. 18 y ss.

33 Iniciativa de Decreto que Reforma Diversos Artículos de la Constitución Política de los Estados Unidos Mexicanos, en Materia de Derechos Humanos, Gaceta Parlamentaria, 5 de mayo de 2004.

34 Corte IDH, Caso Masacre Plan de Sánchez. Reparaciones (artículo 63.1 Convención Americana sobre Derechos Humanos). Sentencia de 19 de noviembre de 2004. Serie C No. 116, párr. 53. 
que en un Estado federal existe una obligación convencional que la víctima de una violación ocurrida en una provincia reciba una reparación integral por parte del gobierno federal o el gobierno local. Esta obligación es independiente de lo que disponga su derecho federal, en particular todo lo relativo a la indemnización. En varios casos ante el sistema interamericano, los gobiernos estaduales han asumido el pago de las indemnizaciones por violaciones a los derechos humanos. ${ }^{35}$

En síntesis, los deberes de respeto y garantía que surgen del artículo 1 son las determinantes al momento de precisar el alcance de las obligaciones de un Estado federal y el artículo 28 de la convención viene a complementar estas obligaciones genéricas. ${ }^{36}$

El artículo 2 de la convención complementa y precisa lo dispuesto en el artículo 1. Requiere que se adopte la legislación necesaria para dar efectividad a las normas convencionales de protección, supliendo eventuales lagunas o insuficiencias del derecho interno, incluidas las originadas en la estructura federal a fin de armonizarlas con las normas convencionales. $^{37}$

El deber general del artículo 2 de la convención americana implica la adopción de medidas en dos vertientes. Por una parte, la supresión de las normas y prácticas de cualquier naturaleza que entrañen violación a las garantías previstas en la convención. Por la otra, la expedición de normas y el desarrollo de prácticas conducentes a la efectiva observancia de dichas garantías. ${ }^{38}$ Ambas vertientes exigen por ende acciones positivas por parte del gobierno federal para asegurar la vigencia efectiva de los derechos y libertades fundamentales en el ámbito de las unidades de la Federación. ${ }^{39}$

35 Véase, por ejemplo, Decreto del Poder Ejecutivo de la Provincia de Mendoza núm. 1.105, de 17 de julio de 1999, autorizando el pago de la indemnización en el caso Garrido-Baigorria ante la corte, Corte IDH, Caso Garrido y Baigorria. Resolución de 27 de noviembre de 2002; Véase CIDH, Informe núm. 31/97, Caso Paulo Christian Guardatti y Decreto núm. 42.793 de 8 de Janeiro de 1998, del Estado de Sao Paulo, autorizando el pago para las víctimas del caso del 42o. Distrito Policial (Parque Sao Lucas). En poder del autor.

36 CIDH, Informe núm. 34/00, Caso 11.291, Carandirú, Brasil, 13 de abril de 2000, párr. 36 e CIDH, Informe sobre la Situación de los Derechos Humanos en Venezuela, 2003, párr. 561.

37 Corte IDH, Exigibilidad del Derecho de Rectificación o Respuesta, Opinión consultiva OC7/86, de 29 de agosto de 1986, párr. 30.

38 Corte IDH, Caso Castillo Petruzzi y otros, Sentencia de 30 de mayo de 1999. Serie C No. 52, párr. 207.

39 Corte IDH, Caso La Ultima Tentación de Cristo, Sentencia del 5 de febrero de 2001, párr. 87. Véase también caso del Tribunal Constitucional, sentencia sobre competencia, 24 de septiembre de 
La mención que realiza el artículo 2 a procedimientos constitucionales implica exclusivamente que los Estados pueden elegir la manera en que se realizará la adecuación de su derecho y práctica sea a nivel federal o de las unidades de la Federación a las obligaciones de la convención. Pero en modo alguno, significa que el Estado puede sustraerse de dichas obligaciones invocando su derecho constitucional. El inciso 2 del artículo 28 en este sentido no es sino la precisión de la obligación general de adoptar medidas con arreglo a las disposiciones de la convención. En el caso de los Estados federales el inciso 2 del artículo 28 exige que la adopción de esas medidas sea realizada de inmediato. El artículo 28 contiene una obligación dirigida a hacer más determinante y cierto el respeto de los derechos convencionales al interior de las federaciones. La obligación que resulta de los artículos 2 y 28.2 complementa pero de ninguna manera sustituye o suple, a la obligación general y no condicionada que resulta del artículo primero de la convención de respetar y garantizar los derechos. ${ }^{40} \mathrm{El}$ propio artículo 2 indica que el Estado debe adoptar medidas con arreglo a las disposiciones de la convención, que para el caso de los Estados federales específicamente están contempladas en el artículo 28 .

La comisión ha aceptado esta interpretación sosteniendo que "estas obligaciones contenidas en los dos primeros artículos de la convención americana son las que imponen al gobierno... la exigencia de "tomar de inmediato las medidas pertinentes, conforme a su constitución y sus leyes, a fin de que las autoridades competentes (de las entidades componentes de la Federación) puedan adoptar las disposiciones del caso para el cumplimiento de esta convención”, en los términos del artículo 28.2.41

\section{El artículo 28 y el deslinde interno de competencias}

Dada la perspectiva que venimos desarrollando, no compartimos la preocupación de algunos comentaristas en el sentido de que la cláusula federal puede implicar una posibilidad de retacear la aplicación de la

1999, párr. 36; Caso Ivcher Bronstein, sentencia sobre competencia, 24 de septiembre de 1999, párr. 37 y caso Hilaire, sentencia sobre excepciones preliminares, 1 de septiembre de 2001, párr. 83.

40 Carnota, Walter, Federalismo y derechos humanos, E. D., pp. 127-911 (el artículo 28 tiene por objeto tornar operativo a nivel local, el principio consagrado en el artículo 2 de la convención, por lo que tiene un carácter instrumental que adapta el texto convencional a la hipótesis de un Estado federal).

41 CIDH, Informe núm. 8/91, Caso 10.180, México, 22 de febrero de 1991, párr. 40. 
convención y hacerla más dificultosa dependiendo de la organización constitucional de los Estados partes ${ }^{42}$ o que podría significar prácticamente la imposibilidad de aplicar la mayor parte de la convención en las unidades de la Federación ${ }^{43}$ o que restringiría notablemente las obligaciones asumidas por los Estados federales en el marco de la convención ${ }^{44}$ o que crea una desigualdad entre los Estados parte de la convención. ${ }^{45}$ Por el contrario, la interpretación de esta cláusula a la luz de la convención americana en su integralidad y de los principios sobre los que se asienta conduce inexorablemente a soslayar toda posibilidad de encontrar en la cláusula federal una eximente de responsabilidad internacional.

La cláusula federal podrá servir para deslindar responsabilidades al interior del Estado federal, pero en modo alguno, para crear un vacío de responsabilidad internacional. ${ }^{46}$ Este deslinde interno de responsabilidades no siempre resulta sencillo. La práctica y jurisprudencia constitucional de países federales está plagada de ejemplos de las complejidades relativas a la exacta distribución de competencias entre autoridades federales y locales. ${ }^{47}$ Además puede exigir que la comisión y la corte deban analizar el derecho interno de los Estados para determinar si en el caso concreto, se trata de "materias sobre las que [el Estado federal] ejerce jurisdicción legislativa y judicial" (artículo 28.1) o "materias que corresponden a la jurisdicción de las entidades componentes de la Federación" (artículo 28.2). ${ }^{48}$ Para decidir con precisión los órganos del sistema deberían analizar si el gobierno federal además de sus obligaciones de respeto y garantía estaba obligado por si mismo a cumplir con "todas las

42 Medina, Cecilia, The Battle of Human Rights. Gross, Systematic Violations and The Inter-American System, Martinus Nijhoff Publishers, p. 100.

43 Gross Espiell, Héctor, La convención americana y la Convención Europea de Derechos Humanos. Análisis comparativo, Jurídica de Chile, pp. 202 y 204.

44 Faundez Ledesma, Héctor, El sistema interamericano de protección de los derechos humanos, Aspectos institucionales y procesales, 3a. ed., 2004, p. 60.

45 Barberis, Julio A., "Consideraciones sobre la Convención Americana sobre Derechos Humanos como tratado internacional", en varios autores, Liber Amicorum en homenaje al juez Héctor Fix-Zamudio, p. 249.

46 Pinto, Mónica, Temas de derechos humanos, Editores del Puerto, p. 74.

47 Véase Buergenthal, Inter-American System, pp. 447 y 448 . Puede verse Colautti, donde analiza como muchas cláusulas de la convención en Argentina son de competencia concurrente en las provincias y el Estado nacional, Colautti, Carlos, El Pacto de San José de Costa Rica, pp. 144 y 145.

48 Aquí, la comisión y la corte se pueden enfrentar al difícil tema de determinar si aceptan la versión oficial del Estado acerca de la interpretación correcta de atribución de competencias entre la Federación y sus entendidas o puede desechar dicha interpretación. 
disposiciones de la presente convención relacionadas con las materias sobre las que ejerce jurisdicción legislativa y judicial" (artículo 28.1) o si por el contrario debía tomar de inmediato las medidas pertinentes, conforme a su constitución y sus leyes, a fin de que las autoridades competentes de las entidades puedan adoptar las disposiciones del caso para el cumplimiento de esta convención (artículo 28.2). Ello debido a que el inciso 1 del artículo 28 remite al derecho interno de las federaciones para atribuir, según el reparto de competencia federal y local, el deber del gobierno federal de cumplir con el tratado dentro de las obligaciones que le son propias. ${ }^{49}$ Mientras que el acápite 2 del artículo 28 complementa al inciso anterior para adjudicar al gobierno federal una obligación de actuar según su Constitución y sus leyes para impeler a los gobiernos locales a adoptar las medidas que les permitan cumplir con la convención. ${ }^{50}$ Si no lo hace el Estado viola la convención al omitir dictar las normas a que está obligado por el artículo $2 . .^{51}$

En uno y otro caso, las obligaciones del gobierno federal pueden ser diferentes pero en modo alguno eliminan sus obligaciones establecidas en los artículos 1 y 2 de la convención, en relación con el artículo 28 de la misma. Lo determinante de todas maneras será precisar si el o los derechos en cuestión fueron respetados y garantizados tal como lo exige el artículo 1 de la convención y si el Estado adoptó las disposiciones de derecho interno (sea éste federal o estadual) para hacer efectivos los derechos y libertades reconocidos en la convención.

\section{Las entidades de la Federación frente a la convención}

\section{americana}

Las provincias carecen de personalidad jurídica internacional y por lo tanto no son técnicamente parte del tratado. ${ }^{52}$ No por ello, pueden desatenderse internamente del tratado celebrado por el Estado federal que las comprende. ${ }^{53}$ De hecho, como ha dicho la Corte Suprema de Justicia

\footnotetext{
49 Bidart Campos, Germán, Tratado elemental de derecho constitucional argentino, t. III, p. 279.

50 Idem.

51 Véase mutatis mutandi, Corte IDH, Opinión Consultiva OC 13/93, Ciertas Atribuciones de la Comisión Interamericana de Derechos Humanos, de 16 de julio de 1993, párr. 26.

52 Barberis, "Consideraciones...," cit., p. 249.

53 Bidart Campos, Tratado elemental..., cit., p. 279.
} 
de la Nación, en Argentina la celebración de un tratado es un acto complejo federal. ${ }^{54}$

Por ello, aún cuando el gobierno central no adopte las medidas necesarias para que sus unidades componentes puedan dar efectividad al tratado, las entidades federales no por ello están eximidas de cumplir con la convención. ${ }^{55}$ Tampoco las entidades federadas quedan desligadas de toda obligación de cumplir con la convención bajo el argumento que el gobierno central es el responsable internacional. ${ }^{56}$

En un caso de una ejecución extrajudicial la comisión aplicó el deber de respeto a las autoridades estaduales junto con la omisión de las autoridades federales de adoptar las medidas pertinentes señalando que las autoridades del estado federado en cuestión no cumplieron con su obligación de hacer respetar el derecho a la vida en este caso. ${ }^{57}$

En un caso concreto relativo a las elecciones en un estado de la unión mexicana, la comisión ha observado las disposiciones constitucionales para sostener que la convención americana es "aplicable en todo el territorio de los Estados Unidos Mexicanos... Las disposiciones de la convención rigen en todos los Estados de la Unión mexicana en calidad de Ley Suprema de toda la Unión", al tenor del artículo. 133 de la Constitución de México. ${ }^{58}$

En sentido concordante, el Comité de Derechos Humanos de Naciones Unidas ha indicado que el sistema de gobierno federal entraña la responsabilidad de las provincias en la observancia de muchos de los derechos previstos en el tratado, que puede requerir la adopción de disposiciones normativas y medidas tomadas en el plano provincial para asegu-

54 Véase, Corte Suprema de Justicia de la Nación, caso Ekmekdjian, Miguel Ángel c/ Sofovich, Gerardo y otros. Fallos 315:1492, consid. 17.

55 Bidart Campos, Tratado elemental..., cit., p. 280.

56 Idem.

57 CIDH, Informe núm. 59/99* Caso 11.405 Newton Coutinho Mendes y Otros, Brasil 13 de abril de 1999, párr. 107.

58 CIDH, Resolución núm. 01/90, Casos 9768, 9780 y 9828 (México) 17 de mayo de 1990, párr. 96 V. Informe Anual de la Comisión Interamericana de Derechos Humanos, 1990-1991, OEA/Ser.L/V/II.79.rev.1, Doc. 12, 22 febrero 1991. Sin embargo, esta interpretación sobre el alcance del artículo 133 de la Constitución de México que varios, incluida la corte suprema de dicho país, han adoptado y que la comisión sigue, ha sido calificada por algún sector de la doctrina como "simplista". Véase, Serna de la Garza, José María, "El poder de celebrar tratados internacionales y la división de competencias del sistema federal mexicano", en id. (ed), Federalismo y regionalismo, 2002, p. 518. 
rar la observancia de los derechos enunciados..$^{59}$ Por eso, el artículo 28 debe entenderse como extendiendo las obligaciones que resultan de la convención americana a cada unidad componente de la Federación. ${ }^{60}$

En el caso argentino, hay varias disposiciones constitucionales que refuerzan el concepto de que las provincias están obligadas a cumplir con las disposiciones de la convención americana y con otros tratados de derechos humanos. Así el artículo 128 al disponer que los gobernadores de provincia son agentes naturales del gobierno federal para hacer cumplir la Constitución y las leyes de la nación, impone claramente una obligación con relación a los tratados ratificados, al menos aquellos mencionados en el artículo 75 inciso 22 de la Constitución. Por supuesto, el artículo 31 que establece la cláusula de la supremacía constitucional indicando que la "Constitución, las leyes de la Nación que en su consecuencia se dicten por el Congreso y los tratados" "son la ley suprema de la Nación; y las autoridades de cada provincia están obligadas a conformarse a ellas, no obstante cualquiera disposición en contrario que contengan las leyes o constituciones provinciales" provee bases más que suficientes para obligar a las provincias a respetar los tratados de derechos humanos ratificados por la Argentina. ${ }^{61}$ Este artículo 31 es similar al artículo 133 mexicano referido en el párrafo anterior y que sirvió de base para que la comisión estableciese la obligatoriedad de la convención americana en todo el territorio mexicano.

En Argentina, un fenómeno interesante que se ha dado con las constituciones provinciales reformadas luego de la reinstauración democrática en 1983 y especialmente luego de la reforma constitucional a nivel nacional de 1994, es el hecho de que las provincias en sus leyes máximas hacen referencia expresa a los tratados internacionales sobre derechos humanos ratificados por el país para reafirmar de una u otra manera que

59 Comité de Derechos Humanos, Observaciones finales: Argentina. 03/11/2000. $\mathrm{CCPR} / \mathrm{CO} / 70 / \mathrm{ARG}$.

60 Colautti, El Pacto de San José..., cit., p. 141.

61 Véase asimismo entre otros el artículo 5 que exige que cada provincia dicte para sí una Constitución.... de acuerdo con los principios, declaraciones y garantías de la Constitución Nacional" y que "bajo de estas condiciones el gobierno federal, garante a cada provincia el goce y ejercicio de sus instituciones" y el artículo 8 que dispone que "los ciudadanos de cada provincia gozan de todos los derechos, privilegios e inmunidades inherentes al título de ciudadano en las demás". 


\section{los derechos reconocidos en los mismos gozan de protección a nivel pro- vincial y vinculan a las autoridades provinciales. ${ }^{62}$}

62 Véase: Constitución de la Provincia de Buenos Aires: Artículo 11. Los habitantes de la provincia son iguales ante la ley, y gozan de los derechos y garantías que establece la Constitución Nacional, los que emanan en su consecuencia a través de los tratados celebrados por la nación y los que se expresan en esta Constitución. Constitución de la Provincia de Corrientes: Artículo 184. Hasta tanto se dicte la legislación pertinente, se aplicará el régimen de la Ley de Amparo para la efectiva protección inmediata y expeditiva de los derechos y garantías contenidos en las cláusulas operativas de los tratados y convenciones internacionales, que hayan sido objeto de ratificación o adhesión por parte de la República Argentina, sin que puedan incluirse o comprenderse otros reclamos con tal motivo. Constitución de la Provincia del Chaco: Artículo 14. Tratados y acuerdos internacionales. Operatividad. Los derechos, deberes, declaraciones y garantías, los acuerdos y tratados mencionados en el artículo 75, inciso 22, enumerados en la Constitución Nacional que esta Constitución incorpora a su texto dándolos por reproducidos, y los que ella misma establece, no serán entendidos como negación de otros no enumerados que atañen a la esencia de la democracia, al sistema republicano de gobierno, a la libertad, la dignidad y la seguridad de la persona humana. Constitución de la Provincia de Chubut: Artículo 22. Las normas relativas a los derechos fundamentales y a las libertades que la Constitución Nacional y la presente reconocen, se interpretan de conformidad con la Declaración Universal de Derechos Humanos, los tratados y los acuerdos internacionales sobre la misma materia ratificados por la nación argentina. Es responsable el funcionario o magistrado que ordene, consienta o instigue la violación de los derechos humanos u omita tomar las medidas y recaudos tendientes a su preservación. La obediencia a órdenes superiores no excusa esta responsabilidad. La Provincia de Chubut mediante la ley 3.746 se adhirió a la Convención Americana sobre Derechos Humanos. Constitución de la Ciudad Autónoma de Buenos Aires: Artículo 10. Rigen todos los derechos, declaraciones y garantías de la Constitución Nacional, las leyes de la nación y los tratados internacionales ratificados y que se ratifiquen. Estos y la presente Constitución se interpretan de buena fe. Los derechos y garantías no pueden ser negados ni limitados por la omisión o insuficiencia de su reglamentación y esta no puede cercenarlos. Artículo 14. Toda persona puede ejercer acción expedita, rápida y gratuita de amparo, siempre que no exista otro medio judicial más idóneo, contra todo acto u omisión de autoridades públicas o de particulares que en forma actual o inminente, lesione, restrinja, altere o amenace con arbitrariedad o ilegalidad manifiesta, derechos y garantías reconocidos por la Constitución Nacional, los tratados internacionales, las leyes de la nación, la presente Constitución, las leyes dictadas en su consecuencia y los tratados interjurisdiccionales en los que la ciudad sea parte. Constitución de la Provincia de Córdoba: Artículo 18. Derechos. Definiciones. Todas las personas en la Provincia gozan de los derechos y garantías que la Constitución Nacional y los tratados internacionales ratificados por la república reconocen, y están sujetos a los deberes y restricciones que imponen. Disposición complementaria Artículo 1. Toda edición oficial de esta Constitución debe llevar anexos los textos de la Declaración Universal de los Derechos del Hombre, de la Organización de las Naciones Unidas de 1948 y la parte declarativa de derechos de la Convención Americana sobre Derechos Humanos (Preámbulo y Parte I), suscripta en San José de Costa Rica en 1969, aprobada por la República Argentina a través de la ley núm. 23054 de 1984, a la cual adhirió esta Provincia de Córdoba por ley núm. 7098 de 1984. Constitución de la Provincia de Neuquén: Artículo 13. Los habitantes de la provincia gozan en su territorio de todos los derechos y garantías enumerados en la Constitución Nacional y en esta Constitución, con arreglo a las leyes que reglamenten su e ejercicio y de los Derechos del Hombre sancionados por la Organización de las Naciones Unidas en París en 1948, los que se dan por incorporados al presente texto constitucional. Constitución de la Provincia de San Juan: artículo 12: La enumeración de libertades, derechos y garantías establecidos en esta constitución, no deben entenderse como la negación de otros derechos, libertades y garantías no 
Al estar obligadas las provincias a dar cumplimiento a las normas contenidas en la convención americana y en otros tratados de derechos humanos, se ha sostenido que la no observancia de los mismos por parte del gobierno provincial podría justificar la intervención federal a la provincia. ${ }^{63}$

La exigencia de la cláusula federal de los tratados de derechos humanos de que las provincias cumplan con los tratados aunado a los principios de supremacía constitucional y de los tratados internacionales constituirían asidero suficiente para que el Estado federal pueda intervenir en

enumeradas, siempre que fluyan del espíritu de ésta, de la Constitución Nacional y de la Declaración Universal de los Derechos Humanos. Constitución de la Provincia de Santiago del Estero: Artículo 1: Forma de gobierno. La Provincia de Santiago del Estero, parte integrante de la República Argentina, con los límites que por derecho le corresponden, es autónoma, democrática y organiza su gobierno bajo la forma republicana y representativa, dando por incorporados a la presente los derechos, declaraciones y garantías de la Constitución Nacional y los tratados y declaraciones internacionales de derechos humanos de jerarquía Constitucional. Reafirma su inquebrantable unidad de destino con las demás provincias y tierras aún irredentas, en el marco del federalismo. Constitución de la Provincia de San Luis: Artículo 11. Todos los habitantes gozan de los derechos y garantías consagrados por esta Constitución de conformidad con las leyes que reglamentan razonablemente su ejercicio. Los principios, declaraciones, derechos y garantías contenidos en ella no pueden ser alterados por disposición alguna. Tales enunciaciones no son negatorias de otros derechos y garantías no enumerados, pero que nacen de la libertad, igualdad y dignidad de la persona humana, de los requerimientos de la justicia social, de principios de la democracia, de la soberanía del pueblo, de la forma republicana de gobierno, de la Declaración Universal de los Derechos Humanos y los tratados universales o regionales de derechos humanos ratificados por la nación. Tampoco se ha de entender como negación de los derechos que la Constitución Nacional acuerda a los habitantes de la nación los cuales quedan incorporados a esta Constitución. Constitución de la Provincia de Tierra de Fuego, Antártida e Islas del Atlántico Sur. Artículo 13. Todas las personas en la provincia gozan de los derechos y garantías que reconocen la Constitución Nacional, los tratados internacionales ratificados por la república y esta Constitución, conforme a las leyes que reglamentan su ejercicio, y están sujetas a los deberes y restricciones que los mismos imponen. En el caso de México puede verse la Constitución del Estado de Hidalgo que en su artículo 9 bis dispone: La Comisión de Derechos Humanos del Estado de Hidalgo, es un organismo descentralizado de la Administración Pública del Estado, con personalidad jurídica y patrimonio propios, de carácter autónomo y de servicio gratuito, encargado de la defensa y promoción de los derechos humanos en el Estado. ...Los derechos humanos a que se refiere el párrafo anterior, son los reconocidos como garantías individuales y sociales establecidas en la Constitución y por las leyes que de ellas emanen; así como los derechos humanos contenidos en los instrumentos internacionales suscritos y ratificados por los órganos correspondientes del Poder Federal.

63 La Constitución argentina en el artículo 6 dispone: El gobierno federal interviene en el territorio de las provincias para garantir la forma republicana de gobierno, o repeler invasiones exteriores, y a requisición de sus autoridades constituidas para sostenerlas o restablecerlas, si hubiesen sido depuestas por la sedición, o por invasión de otra provincia. 
el territorio de una provincia en el caso de incumplimiento grave y sistemático de las normas internacionales. ${ }^{64}$

De modo que en un Estado federal, las normas y prácticas, sean nacionales o provinciales, están sujetas al menos a un doble control. Por un lado al control federal, es decir que no trasciendan el límite constitucional de reparto de competencias entre la Federación y sus entidades componentes. Y por el otro a un control sustantivo para asegurar que son compatibles con las normas internacionales de derechos humanos. ${ }^{65}$

Además, al estar las provincias jurídicamente vinculadas a las normas internacionales de derechos humanos, crea en los estados federales un doble sistema de protección judicial de los derechos. ${ }^{66}$ En efecto, al ser vinculante los tratados de derechos humanos tanto para el Estado nacional como para los provinciales, los tribunales federales como los locales tienen la posibilidad de aplicar y garantizar judicialmente los derechos reconocidos en las normas internacionales. ${ }^{67}$

\section{El principio de no-discriminación y el Estado federal}

Un punto que podría reforzar el argumento que la convención debe tener vigencia en todo el territorio del Estado federal y aplicarse a todas las personas bajo su jurisdicción es el principio de no-discriminación. El argumento sería que si la convención no se aplica de manera igualitaria a

64 Interesantemente la Constitución de Brasil prevé expresamente este supuesto. En efecto, su artículo 34 expresamente señala: “A União não intervirá nos Estados nem no Distrito Federal, exceto para: VII. Assegurar a observância dos seguintes princípios constitucionais: b) direitos da pessoa humana".

65 Véase Sharpe, Robert J., "The Impact of a Bill of Rights on the Role of the Judiciary: A Canadian Perspectiva", en Alston Philip (ed.), Promoting Human Rights through Bills of Rights: Comparative Perspectives, 1999, pp. 438-439 (donde explica las diferentes implicaciones en Canadá de un control sobre los actos de las provincias desde la perspectiva del federalismo y del Canadian Charter of Rights and Freedoms).

66 Woehrling, José, "Convergences et divergentes entre fédéralisme et protection des droits et libertés: 1'exemple des Etats-Unis et du Canada”, (2000) 46 R.D. McGill 21, pp. 39 y ss.

67 Véase por ejemplo Corte de Justicia de la Provincia de San Juan, Expediente núm. 1429/96 “c/ Illanes, Luis Roberto y otro p/ Estafa-Recurso de Queja-Inconstitucionalidad y Casación” del 22 de mayo de 1.998 (declarando inconstitucional el inciso 2 del artículo 438 del Código Procesal Penal (Ley núm. 6.140) en cuanto fija un límite objetivo para la procedencia del recurso de casación por ser contrario al artículo 8.2.h. de la convención americana); Tribunal Superior de Justicia, Sentencia Número: Ciento Cincuenta y Siete, "Suárez Ricardo M. contra Superior Gobierno de la Provincia de Córdoba sobre ejecución de sentencia, apelación recurso de inconstitucionalidad" de del 12 de octubre de 2004 (declarando la inaplicabilidad de la ley provincial 8836 y ordenado el pago de una indemnización en base entre otros considerandos del artículo 4 de la convención americana). 
todas las personas bajo la jurisdicción del Estado podría generarse una situación de discriminación. Ello pues algunas personas bajo la jurisdicción del Estado gozarían de ciertos derechos mientras que otras situadas en otras unidades de la Federación no lo harían.

Diversos organismos de Naciones Unidas han señalado críticamente las disparidades existentes al interior de los países con estructura federal con relación a la vigencia de los diferentes derechos reconocidos. ${ }^{68}$ Específicamente en el caso de Argentina, se comentó que el sistema federal de gobierno confiere a las provincias autoridad en sectores críticos, como la administración de justicia, con el resultado de que el tratado no se aplica de manera uniforme en las diferentes regiones del territorio del Estado. ${ }^{69}$

Sin embargo, la mayoría de los precedentes internacionales no han encontrado que la diversidad de legislaciones o prácticas al interior de un Estado federal implique per se una discriminación. Particularmente en diferentes casos, se utilizó este argumento ante el Comité de Derechos Humanos de Naciones Unidas que a la fecha no lo ha aceptado. Así ha sostenido que: "Al ser el Estado Parte una unión federal, son posibles diferencias entre las partes que constituyen la Federación lo que no constituye por sí mismo una violación al principio de igualdad y no discriminación". 70

68 Comité de los Derechos Económicos, Sociales y Culturales, Conclusiones y recomendaciones, Australia, U.N. Doc. E/C.12/1993/9 (1993), párr. 6; Comité de Derechos Humanos, Observaciones finales: Suiza, U.N. Doc. CCPR/CO/73/CH (2001), párr. 12; Comité de Derechos del Niño, 34o. período de sesiones (2003), Observación general núm. 5. Medidas generales de aplicación de la Convención sobre los Derechos del Niño (artículos 4 y 42 y párrafo 6 del artículo 44), párr. 41

69 Comité de Derechos Humanos, Observaciones finales: Argentina. 03/11/2000. CCPR/CO/ 70/ARG., párr. 8.

70 Sergei Anatolievich Cheban et al. v. The Russian Federation, Communication No. 790/1997, U.N. Doc. CCPR/C/72/D/790/1997 (2001), párr. 7.4 Véase asimismo, el caso Hesse donde se alegó discriminación con base a los diferentes plazos de prescripción en distintas provincias australianas. El Comité declaró inadmisible la petición por falta de fundamentación en este punto. Peter Hesse v. Australia, Comunicación núm. 1087/2002, U.N. Doc. CCPR/C/75/D/ 1087/2002 (2002), párr. 4.2. En el caso Lindgren contra Suecia, donde se alegó discriminación ya que distintos municipios tenían regímenes diferentes en cuanto a subsidios a escuelas privadas, el Comité tampoco encontró violación. Lindgren y otros v. Sweden, Comunicación No. 298/1988, U.N. Doc. CCPR/C/40/D/298/1988 (1990), párr. 10.4. En el caso Arieh Hollis Waldman, los denunciantes alegaron la diferencia de trato entre los residentes en diferentes provincias de Canadá con relación a la educación religiosa, sin que el Comité de Derechos Humanos se pronunciara al respecto. Véase Arieh Hollis Waldman v. Canada, Comunicación núm. 694/1996, U.N. Doc. CCPR/C/67/D/694/ 1996 (1999), párr. 3.1. Véase en el mismo sentido, Corte Europea de Derechos Humanos, caso Dudgeon v. The United Kingdom, 22 de octubre de 1981, Opinión Disidente del juez Matscher 
Solamente la comisión, en un antiguo caso y en el que se discutía la aplicación de la declaración americana y no de la convención, entendió que:

La diversidad en la práctica de los Estados de la Unión — reflejada en el hecho de que algunos de éstos hayan abolido la pena de muerte mientras que otros permiten que ella sea aplicada a niños menores de 10 años de edad - tiene como resultado que se apliquen sentencias totalmente distintas por la comisión de un mismo crimen. La privación de la vida por parte del Estado no debería estar sujeta a un factor tan fortuito como el lugar donde el delito fue cometido...

63. El hecho que el Gobierno de los Estados Unidos deje a discreción de cada Estado de la Unión la aplicación de la pena de muerte al menor de edad ha producido un mosaico de leyes que sujetan la severidad del castigo no a la naturaleza del crimen sino al lugar donde éste se cometió. El ceder a las legislaturas estatales la decisión de si un menor de edad puede ser o no ejecutado no es equivalente a dejar a discreción de cada Estado de la Unión la determinación de la mayoría de edad para adquirir bebidas alcohólicas o para contraer matrimonio. La falla del gobierno federal consiste en no haberse adueñado de la legislación del más fundamental de todos los derechos, el derecho a la vida. De ahí que los Estados Unidos tengan un muestrario de legislación arbitraria que trae como consecuencia la aplicación arbitraria de la privación de los derechos a la vida y a la igualdad ante la Ley, lo cual es contrario a los artículos I y II de la Declaración Americana de los Deberes y Derechos del Hombre, respectivamente. ${ }^{71}$

Una definición tan categórica es problemática pues en muchos países federales, las disposiciones en materia penal son eminentemente una facultad de los gobiernos locales y no del gobierno central. Precisamente es una característica propia de la esencia del federalismo la existencia de diversidad de respuestas dependiendo del lugar donde una situación ocurra así como de un mosaico de legislaciones diferenciadas. Además, excediendo sus competencias, la CIDH hace una evaluación de que materias son propias de la regulación estadual — la determinación de la

indicando: La diversidad de leyes domésticas que es la característica de un Estado federal, nunca puede constituir discriminación y no hay necesidad de justificar la diversidad en este aspecto. Un reclamo en contrario sería irrespetar totalmente la esencia misma del federalismo (traducción propia).

71 CIDH, caso núm. 9647, Estados Unidos, Resolución núm. 3/87, 22 septiembre 1987, párr. 62 y 63 . 
mayoría de edad para adquirir bebidas alcohólicas o para contraer matrimonio - y cual propia de regulación federal - decisión de si la pena de muerte puede ser impuesta a un menor de edad - y cualquiera que sea la respuesta a este último supuesto. ${ }^{72}$

\section{REPARTO DE COMPETENCIAS Y DERECHOS HUMANOS EN LA JURISPRUDENCIA DE LA CORTE SUPREMA DE JUSTICIA DE LA NACIÓN}

En la presente sección realizaremos una revisión somera de la jurisprudencia de la Corte Suprema de Justicia de la nación argentina. El tribunal ha tenido varias oportunidades de referirse a la distribución de competencias y responsabilidades del Estado federal y de los gobiernos provinciales en materia de tratados internacionales de derechos humanos.

A partir del caso Méndez Valles, la corte suprema sostiene que todo lo atinente a la interpretación de los tratados internacionales suscita cuestión federal ${ }^{73}$ a los efectos del recurso extraordinario. ${ }^{74}$ Para llegar a esta conclusión entendió que cuando el país ratifica un tratado se obliga internacionalmente a que sus órganos lo apliquen. Por ello, la prescindencia de las normas internacionales por los órganos internos pertinentes puede originar responsabilidad internacional del Estado argentino. Esta mera posibilidad de generación de responsabilidad internacional configura, de por sí, cuestión federal bastante. Resulta indiferente a los efectos de la eventual responsabilidad internacional aludida, el hecho de que los pre-

72 En efecto, la comisión había decidido previamente que en dicho momento, 1987, no había una norma de derecho internacional que fijara cuál era el límite de edad para imponer la pena de muerte. Véase informe núm. 3/87, párr. 60 La comisión cambiaría acertadamente esta jurisprudencia en el Informe núm. 101/03, Caso 12.412, Fondo, Napoleon Beazley, Estados Unidos, 29 de diciembre de 2003.

73 Una de las formas que la práctica constitucional argentina permite la intervención de la Corte Suprema de Justicia de la Nación es mediante el recurso extraordinario regulado en el artículo 14 de la ley 48. En una innumerable jurisprudencia, la corte suprema ha delineando los requisitos para la procedencia del recurso extraordinario, siendo uno de estos la existencia de una cuestión federal o constitucional. Es decir, que en el caso concreto se encuentre en debate una cuestión federal o constitucional que es aquella que versa sobre la interpretación de la Constitución, leyes federales, tratados o actos federales de autoridades nacionales o la jerarquía de los mismos. Véase Bidart Campos, Germán, Tratado elemental de derecho constitucional argentino, 1993, t. II, pp. 464-466.

74 CSJN, caso Méndez Valles, Fernando c/ A.M. Pescio SCA. s/ ejecución de alquileres, Fallos: 318:2639, consid. 4. En el caso se discutía la interpretación del artículo 36 del Tratado de Derecho Civil Internacional de Montevideo, en particular la ley aplicable a un contrato de alquiler. 
ceptos del tratado cuya violación se invocare funcionen como disposiciones de derecho común y no federal. ${ }^{75}$

En el caso Méndez Valles, considerando adicionalmente la naturaleza de acto federal complejo, ${ }^{76}$ en tanto y en cuanto participan el Poder Ejecutivo y el Congreso, que había sostenido en el ya citado caso Ekmekdjian, sostuvo que la naturaleza federal del tratado alcanza también a su contenido. Es irrelevante que la materia del tratado sea de las calificadas como de derecho común, aun cuando se incorporen las normas del tratado a una ley nacional común. Nada de ello puede enervar la sustancia federal que las disposiciones del tratado poseen en virtud de su fuente internacional. ${ }^{77}$ Por ende, el Estado federal al ratificar tratados asume ciertas obligaciones que normalmente estarían en el marco de competencia de las provincias.

En el área del derecho a la salud, y en particular en los casos Beviacqua $^{78}$ y Monteserín, ${ }^{79}$ la corte suprema sentó la doctrina que el Estado nacional no puede desentenderse de aquellas obligaciones en materia de salud que surgen de los tratados internacionales de derechos humanos bajo el pretexto de la inactividad de otras entidades públicas o privadas, incluidas las provincias.

En el caso Beviacqua, sostuvo que la cláusula federal prevista en la convención americana impone al gobierno nacional el cumplimiento de

75 Ibidem, consids. 6 y 7.

76 Pareciera que en México se sigue esta misma ida, cuando la corte suprema de justicia sostiene que la Constitución ha facultado al presidente de la república a suscribir los tratados internacionales en su calidad de jefe de Estado y, de la misma manera, el Senado interviene como representante de la voluntad de las entidades federativas. Novena Época Instancia: Pleno Fuente: Semanario Judicial de la Federación y su Gaceta Tomo: X, noviembre de 1999 Tesis: P. LXXVII/99 Página: 46 Materia: Constitucional Tesis aislada.

77 Idem caso Méndez Valles, consid. 10. Véase en México en el mismo sentido Novena Época Instancia: Pleno Fuente: Semanario Judicial de la Federación y su Gaceta Tomo: X, noviembre de 1999 Tesis: P. LXXVII/99 Página: 46 Materia: Constitucional Tesis aislada.

78 CSJN. Fallos 323:3235, 24/10/2000, "Campodónico de Beviacqua Ana c/ Min. Salud-Sec. Programa de Salud y Bco. de Drogas Neoplásicas". En este caso se analizó la situación del niño A. S. B. residente de la Provincia de Córdoba, nacido con un padecimiento grave en su médula ósea cuyo tratamiento depende de una medicación especial que le fuera suministrada sin cargo por el Banco Nacional de Drogas Antineoplásicas, dependiente del Ministerio de Salud y Acción Social de la Nación, por dos años hasta su suspensión unilateral por parte del Estado nacional.

79 CSJN. Fallos 324:3571, 16/10/2001, "Monteserín Marcelino c. Estado nacional-M.S. y A.S." En el caso se solicitaba que el Estado nacional disponga la afiliación a la obra social que corresponda, a fin de que pueda recibir todos los beneficios que prevé la legislación vigente de un niño residente en la Provincia de Santa Fe con parálisis cerebral y cuyo padre adoptivo carecía de empleo y estaba en una situación patrimonial difícil que le impedía proveerle el tratamiento médico adecuado. 
todas las obligaciones relacionadas con las materias sobre las que ejerce jurisdicción legislativa y judicial, y el deber de tomar "de inmediato" las medidas pertinentes, conforme a su constitución y sus leyes, para que las autoridades componentes del Estado federal puedan cumplir con las disposiciones de ese tratado (artículo 28 incisos 1o. y 2o.). En adición, la Convención sobre los Derechos del Niño incluye, además, la obligación de los estados de alentar y garantizar a los menores con impedimentos físicos o mentales el acceso efectivo a los servicios sanitarios y de rehabilitación, de esforzarse para que no sean privados de esos servicios y de lograr cabal realización del derecho a beneficiarse de la seguridad social, para lo cual se debe tener en cuenta la legislación nacional, los recursos y la situación de cada infante y de las personas responsables de su mantenimiento (artículos 23, 24 y 26) ${ }^{80}$ El Estado nacional ha asumido, pues, compromisos internacionales explícitos encaminados a promover y facilitar las prestaciones de salud que requiera la minoridad y no puede desligarse válidamente de esos deberes so pretexto de la inactividad de otras entidades públicas o privadas. ${ }^{81}$

La corte suprema leyó entonces la cláusula federal de la convención americana no como excluyente de deberes del gobierno nacional sino que como una obligación adicional con respecto a las provincias. En este sentido, resaltó el más alto tribunal que "frente al énfasis puesto en los tratados internacionales para preservar la vida de los niños, el Estado [nacional] no puede desentenderse de sus deberes haciendo recaer el mayor peso en la realización del servicio de salud en entidades que, como en el caso, no han dado siempre adecuada tutela asistencial". ${ }^{82}$ La corte suprema concluyó que el Estado nacional tiene una función rectora en este campo y debe garantizar la regularidad de los tratamientos sanitarios coordinando sus acciones con los estados provinciales, sin mengua de la organización federal y descentralizada que corresponda para llevar a cabo tales servicios. ${ }^{83}$

En definitiva, el caso Beviacqua estableció dos principios importantes. La responsabilidad primordial del Estado nacional de cumplir con los tratados internacionales de derechos humanos — en este caso mediante la provisión del medicamento o tratamiento respectivo- no libera a 
las provincias de la responsabilidad legal que les cabe en éste área. A criterio del tribunal, además, el principio que el cumplimiento de obligaciones internacionales recae en estos supuestos en el gobierno nacional, no altera no afecta y no es contrario a la distribución de competencias constitucionales en materia federal. ${ }^{84}$

En Monteserín, la corte suprema se basó principalmente en Beviacqua al reafirmar la obligación impostergable que tiene la autoridad pública nacional de garantizar el derecho a la salud con acciones positivas, sin perjuicio de las obligaciones que deban asumir en su cumplimiento las jurisdicciones locales. ${ }^{85}$ Recalcó nuevamente que el Estado nacional no puede desentenderse de sus obligaciones internacionales en este campo bajo el pretexto de la inactividad de otras entidades, incluidas las provincias. El Estado federal es el encargado de velar por el fiel cumplimiento de los derechos a la vida y la salud de los niños reconocidos en tratados ratificados por Argentina a través de la función rectora atribuida por la legislación nacional en ese campo y de las facultades de coordinación e integración con las autoridades provinciales. ${ }^{86}$

El ejercicio de derechos políticos en el ámbito provincial ha sido otra de las áreas en las que la corte suprema ha podido analizar el alcance de las normas de los tratados de derechos humanos con relación a las provincias. Así como con relación al derecho a la salud la corte suprema enfatizó el rol central del gobierno nacional en asegurar su vigencia, en el área de los derechos políticos, el énfasis fue puesto en la obligación de las provincias de cumplir con los tratados internacionales de derechos humanos. La circunstancia que el Estado federal negocia, firma, aprueba y ratifica el respectivo tratado no es eximente de las responsabilidades que le caben a las provincias de cumplir con las normas internacionales. ${ }^{87}$

84 Idem.

85 CSJN, caso Monteserín citado, consid. 11.

86 Ibidem, consid. 13.

87 En México, en la decisión de la corte suprema de justicia que sostuvo por primera vez que los tratados internacionales prevalecen sobre las leyes se indicó asimismo que en el proceso legislativo de aprobación de un tratado internacional, el Senado interviene como representante de la voluntad de las entidades federativas y, por medio de su ratificación, obliga a sus autoridades. Novena Época Instancia: Pleno Fuente: Semanario Judicial de la Federación y su Gaceta Tomo: X, noviembre de 1999 Tesis: P. LXXVII/99 Página: 46 Materia: Constitucional Tesis aislada. Véase Corcuera Cabezut, Santiago, "La incorporación y aplicación de los tratados internacionales sobre derechos humanos en el sistema jurídico mexicano", en Rodríguez-Pinzón y Guevara, Martín (ed.), Derecho internacional de los derechos humanos, 2004 (explicando la prevalencia del tratado sobre 
En Alianza Frente para la Unidad se cuestionó la compatibilidad de la legislación provincial relativa a procesos electorales y las normas del artículo 23 de la convención. El caso permitió a la corte suprema indicar que el deber de garantía que surge del artículo 1 de la convención como el principio de buena fe, exigen que la convención tenga plena vigencia en toda la jurisdicción del Estado, incluidas las provincias. ${ }^{88}$ La corte suprema rechazó el argumento de que la convención "carece de vigencia en el ámbito de los derechos electorales provinciales". Con ello se desconocería que la norma de origen internacional cuenta con jerarquía constitucional. De manera coincidente a nuestra posición, el tribunal indicó que el artículo 1 de la convención obliga al Estado argentino a respetar los derechos reconocidos a toda persona bajo su jurisdicción" incluidos aquellas que están sujetas a regulaciones provinciales. ${ }^{89}$ Afirmar que la vigencia de una norma convencional con jerarquía constitucional se detiene frente a normas locales implicaría además ignorar el artículo 31 de la carta magna que establece la supremacía constitucional y del derecho federal..$^{90}$

la ley local, con excepción de si la ley local prevé una mayor protección del derecho en cuestión). Además, diversos tribunales mexicanos han analizado la compatibilidad de la legislación local con las normas de tratados de derechos humanos. Puede verse entre otros, Novena Época Instancia: Tribunales Colegiados de Circuito Fuente: Semanario Judicial de la Federación y su Gaceta Tomo: XIX, febrero de 2004 Tesis: VII.1o.P.145 P Página: 1068 Materia: Penal Tesis aislada (en el caso se alegaba la contradicción entre el artículo 1 de la Convención sobre los Derechos del Niño que establece que por "niño" se entiende todo ser humano menor de dieciocho años de edad, salvo que en virtud de la ley que le sea aplicable haya alcanzado antes la mayoría de edad y el artículo 34 de la Ley de Adaptación Social y de los Consejos Tutelares para Menores Infractores del Estado de Veracruz que dispone que los menores de dieciséis años son inimputables, con lo que mayores de 16 años son imputables); Novena Época Instancia: Tribunales Colegiados de Circuito Fuente: Semanario Judicial de la Federación y su Gaceta Tomo: XVIII, noviembre de 2003 Tesis: IX.2o.17 A Página: 1021 Materia: Administrativa, Constitucional Tesis aislada (en el caso se estableció la incompatibilidad del artículo 51 de la Ley de Seguridad Pública del Estado de San Luis Potosí que establece que la audiencia ante la Comisión de Honor y Justicia se desarrollará sin abogados con el artículo 8 de la convención americana); Novena Época Instancia: Tribunales Colegiados de Circuito Fuente: Semanario Judicial de la Federación y su Gaceta Tomo: XVI, octubre de 2002 Tesis: XXIII.3o. J/2 Página: 1271 Materia: Constitucional, Penal Juris (en el caso se estableció que el artículo 190 del Código Penal del Estado de Aguascalientes era contrario a la Declaración Universal de Derechos Humanos y al Pacto Internacional de Derechos Civiles y Políticos).

88 CSJN, Caso Alianza Frente para la Unidad, Fallos: 324-3143. En el caso se discutía si una persona procesada pero no condenada tenía derecho a ejercer sus derechos políticos, situación no permitida por la legislación provincial. Considerando 6. Véase Haro, Ricardo, "Los derechos humanos y los tratados que los contienen en el derecho constitucional y la jurisprudencia argentinos", Revista Ius et Praxis, año 9, núm. 1, 2003.

89 Ibidem, consid. 14.

90 Idem. 
Al igual que en el caso Beviacqua, clarificó que con ello no se alteraba la distribución constitucional de competencias entre la nación y las provincias. Fundamentó dicha afirmación en la circunstancia que la convención tiene como propósito consolidar un régimen de respeto por los derechos humanos, estableciendo garantías para las personas y no para beneficio de los estados contratantes. Los Estados asumen varias obligaciones, no en relación con otros Estados, sino hacia los individuos bajo su jurisdicción. ${ }^{91}$

Hooft permitió examinar a la corte suprema la compatibilidad de una norma constitucional provincial con la convención americana. ${ }^{92}$ En efecto, el tribunal declaró inconstitucional el artículo 177 de la Constitución de la Provincia de Buenos Aires, por ser discriminatoria en contravención de un precepto explícito de la convención americana (artículo 23). Para arribar a tal conclusión, la corte suprema, partió por establecer que la norma constitucional provincial cuestionada tenía una presunción de inconstitucionalidad, por establecer una distinción contraria a una de las prohibiciones de la convención americana (en el supuesto el origen nacional). Dicha presunción sólo podría ser remontada por la prueba concluyente de que existe un sustancial interés provincial que la justifique. La corte suprema entendió que las menciones genéricas a principios fundamentes del federalismo, como son las facultades de la provincia para darse sus propias instituciones, la posibilidad de que los requisitos locales puedan ser distintos de los nacionales para cargos judiciales análogos o a que los requisitos y condiciones impugnados resultan de la derivación de lentos procesos históricos y sociales originados por las particularidades propias de cada estado provincial, son "totalmente insuficientes" para justificar la restricción atacada y en todo caso son una dogmática afirmación de la postura de la provincia. ${ }^{93}$

En Partido Justicialista de la Provincia de Santa Fe, la CSJN debió analizar también la compatibilidad de una disposición de la Constitución de la Provincia nuevamente con el artículo 23 de la convención america-

\footnotetext{
91 Idem.

92 Hooft, Pedro Cornelio F. c/Provincia de Buenos Aires, Corte Suprema de Justicia de la Nación, 16 de noviembre de 2004, cons. 2. En el caso se cuestionaba el artículo 177 de la Constitución de la Provincia de Buenos Aires que establecía como requisito para ser juez de cámara "haber nacido en territorio argentino o ser hijo de ciudadano nativo si hubiese nacido en país extranjero".

93 Ibidem, consid. 7.
} 
na. La corte suprema determinó que la exigencia del intervalo de un período para posibilitar la reelección del gobernador y vicegobernador no vulneraba ningún derecho reconocido internacionalmente. ${ }^{94}$ El juez Fayt en su voto separado sostuvo que la incorporación a la Constitución de los tratados internacionales no deroga artículo alguno de la ley fundamental conforme expresamente lo dispone el artículo 75 inciso 22. Por ello, sostuvo el juez Fayt, la forma federal de gobierno (artículo 1 de la Constitución Nacional) y el consecuente reconocimiento de la autonomía institucional de las provincias que el gobierno federal garante (artículo 5 constitucional) no pueden considerarse derogados por la incorporación de convención americana y el Pacto Internacional de Derechos Civiles y Políticos. ${ }^{95}$

En Carranza, relativo al cumplimiento de las recomendaciones contenidas en un informe de la comisión interamericana, ${ }^{96}$ la corte suprema entendió que al menos para determinar si correspondía dicha situación a su competencia originaria, no se requería la intervención de la provincia implicada ya que la recomendación de la CIDH estaba dirigida al Estado nacional y no a la Provincia. ${ }^{97}$ El demandante en dicho caso le había solicitado a la corte suprema que declare que la República Argentina es responsable del cumplimiento del informe referido por ser el responsable ante la comisión interamericana.

El Poder Ejecutivo Nacional tiene la atribución de representar a la República Argentina en el marco de aquellos asuntos que puedan involu-

94 CSJN, Fallos 317:1195, Partido Justicialista de la Provincia de Santa Fe contra Santa Fe Provincia sobre acción declarativa, consid. 4.

95 Idem, voto del señor ministro Carlos S. Fayt, consid. 21. En su voto el juez Fayt analizó el alcance del Informe núm. 30/93 de la Comisión Interamericana de Derechos Humanos, relativa a la prohibición constitucional guatemalteca de optar por el cargo de presidente a caudillos o jefes de un golpe de Estado, revolución armada o movimiento militar que haya alterado el orden constitucional ni quienes como consecuencia de tales hechos asuman la jefatura de gobierno. Véase CIDH, Informe núm. 30/93, Caso 10.804, Efraín Ríos Montt, Guatemala, 12 de octubre de 1993.

96 CIDH, Informe núm. 30/97, Caso 10.087, Gustavo Carranza, Argentina, 30 de septiembre de 1997.

97 CSJN, Carranza Latrubesse, Gustavo c/ Chubut, Provincia de y otro s/ acción declarativa de certeza, 12 de marzo de 2002. En México se ha sostenido que en una controversia constitucional en la que se cuestiona la invalidez de un tratado internacional no debe llamarse a juicio a los tres poderes federales y a todas y cada una de las entidades federativas, es decir, al Estado mexicano, sino solamente las autoridades integrantes de los poderes de la Federación que intervinieron en su proceso de formación, como representantes de toda la nación. Novena Época Instancia: Pleno Fuente: Semanario Judicial de la Federación y su Gaceta Tomo: XX, septiembre de 2004 Tesis: P./J. 85/2004 Página: 1257 Materia: Constitucional Jurisprudencia. 
crar la responsabilidad del país en la esfera internacional incluidas las consecuencias que podría traer aparejado el cumplimiento o incumplimiento de las recomendaciones que la comisión emite. ${ }^{98}$ Por lo tanto el Ejecutivo nacional y no la provincia es el legitimado pasivo de la pretensión. ${ }^{99}$ Sólo el Estado nacional en tanto destinatario natural de la recomendación de la CIDH, y ningún otro en su lugar, como Estado parte de la convención, es quien debe valorar el reclamo que se realiza y, en su caso, cumplir con los deberes inherentes a esa calidad. Al ser un caso decidido por la comisión, el asunto salió de la órbita interna argentina y por lo tanto la provincia no puede contradecir el objeto de la controversia planteada judicialmente. ${ }^{100}$ La corte suprema consideró especialmente que todo el informe de la comisión da cuenta que la parte involucrada era el Estado nacional y a quien se destinaban las recomendaciones y no así a la Provincia de Chubut. ${ }^{101}$

La decisión en Carranza parecería limitar en algo el alcance de las responsabilidades que la corte suprema argentina le había asignado a las provincias en el cumplimiento de las obligaciones internacionales. Sin embargo, entendemos que la decisión fue exclusivamente en una materia procesal (la competencia originaria de la corte para analizar el exclusivo pedido del actor) ${ }^{102}$ y no sustantiva en cuanto a si la provincia en su momento debería adoptar alguna acción para cumplir con las recomendaciones formuladas por la comisión. Por eso, en dos oportunidades, la corte suprema sostuvo que en el estado procesal en que se encontraba la causa (es decir la determinación de la competencia) no se requería la intervención de la provincia sin perjuicio de las eventualidades procesales que pudiesen configurarse dependiendo de la respuesta que el Estado nacional diese en su oportunidad. ${ }^{103}$

98 Ibidem, caso Carranza, consid. 5.

99 Ibidem, consid. 6.

100 Idem.

101 Ibidem, consid. 7.

102 La corte suprema en adición al recurso extraordinario explicado en nota 187 interviene originaria y exclusivamente en todos los asuntos concernientes a embajadores, ministros y cónsules extranjeros, y en los que alguna provincia fuese parte de conformidad con el artículo 117 de la Constitución argentina.

103 Caso Carranza, consids. 3 y 4. 
Finalmente, en el área de condiciones de detención, hay dos casos que involucran a la Provincia de Buenos Aires. ${ }^{104}$ El caso Artigué se refiere a un conflicto entre la Sala III de la Cámara Federal de Apelaciones de La Plata y la Sala II de la Cámara de Apelación en lo Criminal y Correccional de La Plata, capital de la Provincia de Buenos Aires. La disputa se originó ante las denuncias por malos tratos por parte de funcionarios del servicio penitenciario provincial y temor por la seguridad personal de Artigué que motivó que la Cámara Federal sustrajera al detenido de la jurisdicción provincial y decidiera que se alojara en el sistema penitenciario federal, entre otros motivos invocando el artículo 13 de la Convención contra la Tortura que dispone que cualquier denuncia sobre tortura debe ser pronta e imparcialmente examinado por sus autoridades competentes. ${ }^{105}$ Llegada la disputa a la corte suprema, ésta decidió a favor de la jurisdicción del tribunal local. Entendió que la justicia provincial era la competente ya que sería inconstitucional impedir a los magistrados locales considerar y aplicar en su integridad la totalidad del orden jurídico del Estado, en cuya cúspide se encuentra la Constitución Nacional, las leyes federales y los tratados internacionales, a las que las autoridades provinciales están obligadas a conformarse, no obstante cualquier disposición en contrario que contengan sus constituciones o leyes. ${ }^{106} \mathrm{~A}$ criterio de la corte suprema, la disposición de la Convención contra la Tortura que exige que una denuncia sobre hechos de tortura sea pronta e imparcialmente examinada por las autoridades competentes, encuentra realización en el derecho público argentino por medio de la pertinente división de jurisdicciones que derivan del régimen federal de gobierno. De ello se desprende que la justicia federal carece de jurisdicción para conocer en la denuncia del hecho emanado de autoridad local. ${ }^{107}$

Artigué limita la competencia de la justicia federal pero al mismo tiempo reafirma el deber de los jueces provinciales de control adecuado sobre las condiciones de detención del procesado, incluidas las reglas de

104 No sorprende que la corte suprema haya debido intervenir en casos de detención en la Provincia de Buenos Aires debido a la gravedad de la situación. Véase notas 38 y 39. Véase también CSJN. Fallos 318:2002 donde la corte suprema intervino a raíz de la muerte de 35 detenidos alojados en la cárcel de Olmos en la Provincia de Buenos Aires.

105 CSJN, Competencia núm. 281. XXV, Artigué, Sergio Pablo-incidente de restitución de detenido, 25 de marzo de 1994. Es importante notar que esta decisión es anterior a la reforma constitucional de 1994 por algunos meses.

106 Considerando 11.

107 Considerando 12. 
la Convención contra la Tortura. Este deber de control provincial fue reafirmado una década después en Verbistky, indudablemente el caso más importante resuelto por la corte suprema en este tema. ${ }^{108}$ La corte suprema en primer lugar reafirma su jurisprudencia en el sentido que existe cuestión federal suficiente pues se cuestiona, entre otros, la inteligencia y el alcance otorgado a diversas normas contenidas en los tratados, convenciones y documentos internacionales que forman parte del bloque constitucional. Al igual que en Méndez Valles, afirma que el recurso extraordinario ante ella es procedente pues del resultado del caso se puede comprometer la responsabilidad del Estado argentino frente al orden jurídico supranacional. ${ }^{109}$

Uno de los elementos más importantes de la sentencia es la reafirmación de que las normas internacionales son vinculantes y por lo tanto pueden ser violadas por la provincia. ${ }^{110}$ Para sostener este principio, la corte suprema utilizó principalmente como punto de referencia no un tratado internacional ratificado por Argentina sino las Reglas Mínimas para el Tratamiento de Reclusos de las Naciones Unidas, ${ }^{111}$ a las que si bien no les reconoció jerarquía constitucional, entendió que por vía del artícu-

108 CSJN, Recurso de hecho deducido por el Centro de Estudios Legales y Sociales en la causa Verbitsky, Horacio s/ habeas corpus, 3 de mayo de 2005. En el caso se debatía la procedencia de un hábeas corpus colectivo presentado por el Centro de Estudios Legales y Sociales cuestionando varios aspectos de la situación de las personas privadas de su libertad en la Provincia de Buenos Aires. La corte interamericana ha considerado esta decisión de la corte suprema "relevante" al momento de analizar la situación de las personas privadas de su libertad en la Provincia de Mendoza. Resolución de la Corte Interamericana de Derechos Humanos, de 18 de junio de 2005, medidas provisionales, Caso de las Penitenciarías de Mendoza, consid. 10. El presidente de la corte interamericana, juez Sergio García Ramírez en su voto razonado también se refirió positivamente a la decisión "de la respetable Corte Suprema de Justicia de la Argentina". Voto concurrente del juez Sergio Garcia Ramirez, párr. 11.

109 Consid. 13.

110 Consid. 39. En este aspecto, también los jueces que votaron en disidencia parcial o total, coincidieron en que las provincias claramente se hallan vinculadas por la normativa internacional. Véase disidencia parcial del señor ministro doctor don Carlos S. Fayt, consid. 27; Véase disidencia parcial de la señora ministra doctora Doña Carmen M. Argibay, consid. 57(el examen de constitucionalidad del régimen de la prisión preventiva y la excarcelación vigente en la Provincia de Buenos Aires debe llevarse a cabo exclusivamente sobre la base de las reglas contenidas en la Constitución federal y en los instrumentos internacionales que vinculan a las legislaturas provinciales)y disidencia del señor ministro doctor don Antonio Boggiano, consid. 8 (las provincias no son ajenas al cumplimiento de los tratados internacionales sobre derechos humanos).

111 Reglas Mínimas para el Tratamiento de los Reclusos, adoptadas por el Primer Congreso de las Naciones Unidas sobre Prevención del Delito y Tratamiento del Delincuente, celebrado en Ginebra en 1955, y aprobadas por el Consejo Económico y Social en sus resoluciones 663C (XXIV) de 31 de julio de 1957 y 2076 (LXII) de 13 de mayo de 1977. 
lo 18 de la Constitución ${ }^{112}$ se han convertido en el estándar internacional respecto de personas privadas de libertad. ${ }^{113}$

Desde esta perspectiva, al igual que en casos anteriores, la corte suprema entiende que la legislación provincial puede ser inconstitucional por ser incompatible con la normativa internacional. ${ }^{114}$ La corte suprema no se limita a establecer que la provincia se halla vinculada a la normativa internacional sino que decide ordenar a las autoridades provinciales una serie de medidas destinadas precisamente a adecuar su legislación y su práctica a dichos estándares. El abanico de medidas ordenadas posiblemente no tenga precedentes en la historia jurisprudencial argentina. Ellas van desde encomendar a la Provincia de Buenos Aires para que a través de su Ministerio de Justicia organice la convocatoria de una mesa de diálogo a la que invitará a la accionante y restantes organizaciones presentadas como amicus curiae, sin perjuicio de integrarla con otros sectores de la sociedad civil que puedan aportar ideas y soluciones y que en un ámbito de discusión facilitada permita arribar a soluciones consensuadas y sustentables; ${ }^{115}$ instruir a la suprema corte y a los demás tribunales de la Provincia de Buenos Aires para que en sus respectivas competencias extremen la vigilancia para el adecuado cumplimiento de las reglas mínimas y de las normas que nacional e internacionalmente imponen el tratamiento digno de toda persona privada de libertad y, en especial, en lo que hace a la tutela de la vida humana y la integridad física de los presos, del personal y de terceros ${ }^{116}$ y para hacer cesar con la urgencia del caso el agravamiento o la detención misma ${ }^{117}$ y disponer, sin dilación, que en un plazo perentorio, la Corte Suprema de la Provincia de Buenos Aires haga cesar la presencia de adolescentes y enfermos en comisarías o establecimientos policiales; ${ }^{118}$ exhorta a los poderes Legislativo y Ejecutivo de la Provincia de Buenos Aires a que adecuen la legislación procesal penal en materia de prisión preventiva y excarcelación, y

112 En la parte pertinente el artículo 18 de la Constitución Argentina estipula: Las cárceles de la nación serán sanas y limpias, para seguridad y no para castigo de los reos detenidos en ellas, y toda medida que a pretexto de precaución conduzca a mortificarlos más allá de lo que aquélla exija, hará responsable al juez que la autorice.

113 Consid. 39

114 Consid. 58. La corte suprema no declaró la inconstitucionalidad de la legislación provincial por motivos procesales.

115 Consid. 26.

116 Consid. 40.

117 Consid. 41.

118 Consid. 42. 
ejecución penal a los estándares mínimos internacionales que, a modo de ejemplo, recepta la legislación procesal penal y de ejecución penal de la nación. ${ }^{119}$ La posibilidad de que se comprometiese la responsabilidad internacional del Estado federal sirvió de justificación para que la corte suprema ordenara a las autoridades provinciales las medidas reseñadas. ${ }^{120}$

Una de las particularidades de los sistemas federales es la posibilidad de que entre las distintas unidades de la Federación y entre éstas y el ámbito federal existan ciertas diferencias en la manera en que se tratan diferentes cuestiones. Sin embargo, Verbitsky restringió enormemente esta posibilidad de divergencias indicando que el Estado federal ejerce cierto grado de legislación y orientación en materia procesal, con el fin de lograr un mínimo equilibrio legislativo que garantice un estándar de igualdad ante la ley. ${ }^{121}$ Es interesante resaltar que la corte suprema menciona el principio de igualdad, pues como llevamos dicho, hasta ahora los órganos internacionales - con la salvedad del solitario caso de la CIDHno han entendido que estas divergencias entre las unidades federativas constituya un supuesto de discriminación. ${ }^{122}$ Sin embargo, el alto tribunal entiende que

Cualquiera sea el sistema procesal de una provincia y sin desmedro de reconocer su amplia autonomía legislativa en la materia, lo cierto es que si bien no puede llevarse la simetría legislativa hasta el extremo de exigir una completa igualdad para todos los procesados del país, la desigualdad tampoco puede extremar las situaciones hasta hacer que el principio federal cancele por completo el derecho a la igualdad ante la ley, pues un principio constitucional no puede borrar o eliminar otro de igual jerarquía. ${ }^{123}$

Para lograr esta uniformidad la corte entiende que las provincias se hallan sometidas a un piso mínimo determinado por los estándares internacionales a los que se ajusta la legislación nacional. ${ }^{124}$

119 Consid. 58 y 60.

120 Consids. 41 y 42. En su disidencia parcial, el juez Fayt concordó con las pautas orientativas dadas por la mayoría, pero en el entendimiento que las mismas son orientaciones para los jueces locales que son quienes deben decidir todas estas cuestiones.

121 Consid. 55. La jueza Argibay disintió en este aspecto de la decisión mayoritaria ya que no cree que la legislación nacional deba servir de marco para el análisis de la legislación provincial. Pero coincidió con la mayoría en que la normativa internacional vincula a las provincias.

122 Véase notas 179 a 183 y texto que acompañan.

123 Consid. 57.

124 Idem. 
La lectura conjunta de estos fallos permite afirmar que la corte suprema ha tomado los puntos centrales defendidos en este trabajo. Toda la materia regulada por tratados de derechos humanos ratificados por Argentina, por tal motivo configuran de por sí una cuestión federal y no de derecho común. Si bien en los casos reseñados, tal doctrina se utilizó para habilitar la jurisdicción de la corte suprema una consistencia con dicha doctrina permitiría también que el Congreso Nacional pudiese adoptar la legislación que fuese necesaria para dar efectividad a los derechos reconocidos en los tratados de derechos humanos y que el Ejecutivo pudiese actuar en este ámbito. La principal preocupación de la corte suprema tanto al asumir su jurisdicción como al resolver sustantivamente los casos es la eventual generación de responsabilidad internacional del Estado. Y en este sentido, puede incluso el tribunal ordenar a las autoridades provinciales la adopción de medidas específicas para adecuarse al marco internacional incluso en materias que les están tradicionalmente reservadas. Desde esta perspectiva, la jurisprudencia de la corte suprema ha conciliado la estructura federal argentina con las obligaciones que surgen de los tratados ratificados.

En segundo lugar, la jurisprudencia de la corte suprema atribuye una clara responsabilidad central al gobierno federal por asegurar y cumplir las obligaciones que surgen de los tratados de derechos humanos. En este sentido, no puede desatenderse el gobierno federal de sus obligaciones argumentando que las mismas caen bajo la competencia de las provincias. En tercer lugar, y complementando el punto anterior, la corte suprema también ha indicado que las provincias, están sujetas a las disposiciones de los tratados de derechos humanos. Por ello, tanto su Constitución como su legislación infraconstitucional y sus actuaciones no pueden ser incompatibles con los requerimientos que emergen de la normativa internacional. Finalmente, el máximo tribunal deja muy claro en esta línea jurisprudencial que el cumplimiento por parte del gobierno federal o de los provinciales de las normas internacionales de derechos humanos, al menos aquellas con jerarquía constitucional no afecta la distribución constitucional de competencias en materia federal.

Esta jurisprudencia argentina es de suma importancia pues impide al Estado o gobierno nacional desligarse de sus obligaciones internacionales bajo el pretexto que su cumplimiento cae bajo la esfera de las provincias y a éstas últimas les impone la obligación de cumplir con los tratados de derechos humanos. Sin embargo, casos como Beviacqua, 
Monteserín, Verbitsky ponen en evidencia que en la Argentina se carece de un mecanismo institucional efectivo que permita la coordinación entre el gobierno nacional y los provinciales en materia de cumplimiento de las obligaciones internacionales en materia de derechos humanos. Tampoco se cuenta con un mecanismo que permita la revisión previa a la aprobación o ratificación de los tratados o posterior a ella, de legislación provincial contraria a las normas internacionales como lo atestigua el caso Hooft. ${ }^{125}$ Finalmente, Carranza es un ejemplo de la falta de un mecanismo que permita el cumplimiento de decisiones de órganos internacionales cuando están en juego competencias del gobierno nacional y provincial.

\section{EL ESTADO ARGENTINO, LOS GOBIERNOS PROVINCIALES Y LA COMISIÓN INTERAMERICANA}

Tal como se indicó precedentemente, la comisión interamericana ha debido conocer una serie de casos argentinos relativos a alegadas violaciones a los derechos humanos ocurridas en el ámbito provincial y cuya responsabilidad primaria a nivel interno se atribuye a las autoridades provinciales.

Como parte de una estrategia global de los sucesivos gobiernos de la Argentina desde la reinstauración de la democracia en 1983, 126 en varios de estos casos se ha procurado alcanzar una solución amistosa entre los peticionarios y el Estado con la participación de las autoridades provinciales respectivas. En realidad, también otros Estados federales como han alcanzado soluciones amistosas en casos que involucraban a las autoridades locales. ${ }^{127}$

125 Barberis interpreta que el artículo 28 de la convención americana en realidad se refiere a su ratificación, en el sentido de que el Estado federal debería procurar que las entidades locales adopten las medidas necesarias para cumplir con la convención y recién cuando esto se logre, el Estado ratificaría el tratado. Barberis, "Consideraciones...", cit., p. 250.

126 Véase Presentación del Embajador Jorge Taiana en Sesión de Trabajo sobre la Implementación de los Compromisos y los Estándares Internacionales de los Derechos Humanos en el Sistema Interamericano, 1 de marzo de 2003, CIDH-IJP, pp. 69 y ss.

127 Véase por ejemplo, Informe núm. 95/03, Petición 11.289, Solución Amistosa, José Pereira, Brasil, 24 de octubre de 2003 (relativo a trabajo esclavo en el Estado de Pará). Debe destacarse que el acuerdo fue concluido entre el Estado brasilero y los peticionarios sin intervención de las autoridades del Estado de Pará donde ocurrieron los hechos. El gobierno federal asumió la responsabilidad, el pago de la indemnización, el compromiso de continuar con las investigaciones 
Alcanzar soluciones amistosas en el caso de hechos ocurridos a nivel provincial ha demostrado ser sumamente dificultoso y los resultados han sido variados. Precisamente por estas mismas dificultades la gran mayoría de los casos argentinos que involucran a autoridades provinciales aún no han logrado solucionarse a pesar de que las negociaciones se han venido desarrollando por años. Los problemas vienen asociados a una conjunción de carencias. Una de las principales falencias es la ausencia de conciencia de muchas autoridades sobre temas de derechos humanos y por ende una falta de voluntad política para solucionarlos. Por su parte, los distintos gobiernos nacionales no han mostrado siempre su decidido involucramiento para lograr resolver por sí o por medio de las autoridades provinciales las denuncias internacionales. Esta conjunción produce que estructuralmente se carezca de un marco institucional y legal sólido, consensuado y eficaz entre el gobierno nacional y los gobiernos provinciales que permita tanto prevenir violaciones como responder frente a denuncias internacionales. El Consejo Federal de Derechos Humanos que existe en el marco del Ministerio de Justicia y en el que hay representantes de todas las provincias y del gobierno nacional jamás ha logrado cumplir este rol. ${ }^{128}$ En el aspecto de las soluciones amistosas especialmente se carece de pautas sobre quien representa al Estado, quién debe firmar los acuerdos alcanzados, qué puede y debe hacer el Estado nacional en caso de que la provincia no tenga la voluntad de solucionar amistosamente el asunto, por ejemplo porque no desee juzgar a los presuntos responsables, porque no pague las indemnizaciones correspon- dientes, porque no modifique la legislación impugnada, entre otros.

Hay dos casos que involucraron a autoridades provinciales que lograron concluirse amistosamente gracias a la decisión del gobierno nacional y provincial respectivo, al involucramiento activo de la CIDH, a la flexibilidad de los denunciantes y a pesar de la carencia del espacio institucional y régimen legal que mencionamos.

El primero es el caso de Paulo Christian Guardatti quien en la madrugada del 23 de mayo de 1992, Paulo Christian Guardatti se encontraba en un baile en la localidad de Estanzuela, de la Provincia de Mendoza, junto con un grupo de amigos. Discutió en el lugar con un policía uniformado, a

penales y de reformar la legislación, sin ningún compromiso concreto para las autoridades locales. Véase Informe núm. 95/03, párr. 24.

128 En ninguno de los casos mencionados en esta sección o en las notas 27 a 30, el consejo federal ha tenido intervención formal e institucional alguna. 
quien volvió a encontrar más tarde en ropas deportivas y se produjo un segundo incidente a las 04:30 de la madrugada del día siguiente. En dicho momento, el policía realizó disparos al aire con su revólver, motivo por el cual los acompañantes de Guardatti se alejaron corriendo, pero éste permaneció inmóvil. Inmediatamente fue alcanzado por el policía, quien lo llevó esposado a un destacamento policial distante tres cuadras del lugar. Varios testigos presenciaron el suceso y aportaron una descripción del policía. Desde ese momento no se volvió a ver con vida a Guardatti. ${ }^{129}$

Luego de meses de investigación, la Quinta Cámara del Crimen de la Provincia de Mendoza declaró la nulidad del procesamiento de varios policías implicados y ordenó su liberación. ${ }^{130}$ Ante esta situación de impunidad, se presentó una denuncia ante la CIDH. En su primera respuesta, el Estado señaló, entre otras circunstancias, que los hechos ocurrieron en la jurisdicción provincial, "lo que conduce a la actuación de poderes propios de la provincia que el Estado nacional no puede avasallar". ${ }^{131}$ Agregaría en su segunda presentación que había notificado formalmente al Gobierno de la Provincia de Mendoza, en cumplimiento del artículo 28 de la convención americana. ${ }^{132}$

Luego de intensas negociaciones, el 31 de mayo de 1996 representantes del gobierno nacional y provincial firmaron con los peticionarios un acuerdo común a los casos Guardatti y Garrido-Baigorria. El acuerdo se refiere a dos aspectos principales: la indemnización y la investigación. ${ }^{133}$

En cuanto al aspecto indemnizatorio, se creó un Tribunal Arbitral para determinar el monto indemnizatorio, cuyos miembros serán designados

129 CIDH, Informe núm. 31/97, Caso 11.217, Paulo C. Guardatti, Argentina, 14 de octubre de 1997, párr. 2.

130 Ibidem, párr. 3, 4 y 5.

131 Ibidem, párr. 8.

132 Ibidem, párr. 10.

133 Ibidem, párr. 19. Durante la tramitación del caso, la comisión celebró una audiencia en el presente caso, con participación de los peticionarios y el Estado, en que se sentaron las bases preliminares para una solución amistosa (párr. 15). Luego de una serie de negociaciones, en las que participaban tanto el gobierno nacional como el provincial, se firmaron un acta de acuerdo entre los peticionarios y el subsecretario de Justicia de la Gobernación de Mendoza, así como un borrador de acuerdo fue elaborado el 26 de diciembre de 1995 como base para la solución amistosa (párr. 16). El 24 de enero de 1996 el presidente de la República Argentina emitió un decreto en virtud del cual designa a un agente para negociar la solución amistosa en este caso 11.217 y en el caso Garrido y Baigorria, en trámite ante la corte interamericana y que también se refería a dos desapariciones en la Provincia de Mendoza. En el mismo decreto se invita al Gobierno de la Provincia de Mendoza a participar de la negociación (párr. 17). Véase Decreto del Poder Ejecutivo Nacional núm. 53/96, de 30 de enero de 1996, en poder del autor. 
por consenso entre los integrantes de la Comisión Asesora del Consejo de la Magistratura para la Materia Civil y Comercial de la Provincia de Mendoza. El fallo debía ser dictado ajustándose a "las pautas internacionales en vigor" y sería sometido a la homologación de los organismos internacionales intervinientes, y las partes podrían objetarlo en caso de arbitrariedad. ${ }^{134}$ El 25 de junio de 1996 fue emitido el fallo arbitral. El fallo arbitral fue rechazado por los abogados de la familia de la víctima alegando arbitrariedad por no haberse seguido las pautas fijadas en el acuerdo. ${ }^{135}$ Sin embargo, la comisión analizó el fallo y concluyó que no se había constatado la arbitrariedad invocada. ${ }^{136}$

El segundo aspecto del acuerdo se refiere a la investigación y consistió fundamentalmente en la creación de una Comisión ad-hoc de investigación integrada por cinco miembros designados por consenso para averiguar lo sucedido en ambos casos, y emitir un dictamen al respecto que sugiera las medidas a ser tomadas. ${ }^{137}$ Con fecha 16 de agosto de 1996, la Comisión ad-hoc de investigación presentó su informe a la Suprema Corte de Justicia de Mendoza y al secretario ejecutivo de la comisión interamericana. El informe analizó todas las circunstancias que rodearon la detención y posterior desaparición de Guardatti, así como las actuaciones judiciales de primera y segunda instancia que culminaron en el sobreseimiento de los imputados. ${ }^{138}$ La Comisión ad-hoc formuló una serie de recomendaciones específicas relativas a los casos como a medidas generales de prevención. ${ }^{139}$

La comisión luego de concluir que se habían cumplido los puntos previstos en las dos partes del acuerdo destinado al logro de una solución amistosa en el presente caso, toma nota de que aún no se ha sancionado a las personas señaladas en el informe de la Comisión ad-hoc y por eso decide continuar con la supervisión del cumplimiento de las medidas pendientes. ${ }^{140}$

A lo largo del informe, la comisión refleja el involucramiento del Gobierno de la Provincia de Mendoza. Particularmente, en nuestro criterio, la CIDH procuró dejar claro que es el gobierno provincial antes que el nacio-

134 Ibidem, párr. 19.

135 Ibidem, párr. 26 y 27.

136 Ibidem, párr. 36 y 38.

137 Ibidem, párr. 19.

138 Ibidem, párr. 29.

139 Ibidem, párr. 32.

140 Ibidem, párr. 40 y 41 y punto resolutivo 2. 
nal quien debía cumplir con las obligaciones pendientes. Así, la comisión en una situación de la que no conocemos ningún otro precedente, remitió el 27 de agosto de 1997 una nota al Ministerio de Relaciones Exteriores de Argentina, para ser entregada al gobernador de Mendoza. En dicha comunicación, la comisión solicitó información específica respecto a las medidas adoptadas por el gobierno de Mendoza para cumplir con las recomendaciones de la Comisión ad-hoc, así como el estado de las investigaciones para determinar el paradero de los restos de Paulo Christian Guardatti; igualmente, solicitó un compromiso del gobierno provincial sobre el pago expedito de las indemnizaciones. ${ }^{141}$ Asimismo, la comisión resolvió recomendar al Estado argentino, y por su intermedio al Gobierno de la Provincia de Mendoza, la publicación y difusión amplia del informe de la Comisión ad-hoc del 16 de agosto de 1996. ${ }^{142}$

Finalmente, la comisión expresó su reconocimiento al Estado argentino por haber designado una agente para la solución amistosa del presente caso, y por haber proveído todos los recursos humanos y materiales a tal efecto; y al Gobierno de la Provincia de Mendoza por la decidida colaboración prestada para el mismo fin. ${ }^{143}$

Interesantemente en el otro caso que integraba el acuerdo de solución amistosa y que se hallaba ante la corte interamericana, el tribunal internacional resolvió de manera diametralmente opuesta a la CIDH. En efecto, la corte no consideró que se había configurado un supuesto acuerdo de voluntades. Entre otras consideraciones, el tribunal con un formalismo desconocido sostuvo que no había solución amistosa debido a que el acuerdo habría sido suscripto por el gobierno provincial y no por el Estado nacional y por que el decreto provincial mendocino ratificaba ese acuerdo como si fuese una de las partes en los términos del artículo 28 de la convención. ${ }^{144}$ La corte desconoció que el citado acuerdo fue firmado en la sede del Ministerio de Relaciones Exteriores de Argentina, entre

141 Ibidem, párr. 41.

142 Ibidem, punto resolutivo 1.

143 Ibidem, párr. 44.

144 Caso Garrido y Baigorria, Resolución de la corte de 31 de enero de 1997, párr. 15, reimpreso en Informe Anual de la Corte Interamericana de Derechos Humanos 1997, OEA/Ser.L/V/III.39, doc. 5 (1998). Véase Decreto de la Provincia de Mendoza núm. 673/96. En los considerandos de dicho decreto se menciona que la Provincia de Mendoza ostenta el carácter de estado obligado a través de la cláusula federal contenida en el artículo 28 de la convención americana, por lo que contribuye con la nación en las negociaciones que ella realiza y coadyuva al cumplimiento de sus obligaciones internacionales. 
otros por la agente del gobierno argentino designada para el caso Garrido-Baigorria ante la corte. ${ }^{145}$ También la corte desconoce que el propio presidente de la República Argentina, había autorizado la realización de estas negociaciones y había establecido que las mismas serían ratificadas por el Poder Ejecutivo nacional. ${ }^{146}$

La segunda solución amistosa se refiere al caso Juan Ángel Greco. ${ }^{147}$ Según las constancias del expediente, el 25 de junio de 1990, el señor Greco fue detenido y transportado a la Comisaría de Puerto Vilelas, Provincia del Chaco, dónde fuera golpeado por los funcionarios policiales. El señor Greco no fue informado de las razones de su detención ni de sus derechos, y la policía no dio cuenta prontamente de la detención al juez local de turno. ${ }^{148}$ Aproximadamente a la una de la mañana estalló un incendio en su celda, supuestamente provocado por los propios policías. Como consecuencia del cual el señor Greco sufrió graves quemaduras y pese a la gravedad de las lesiones sufridas, pasaron horas antes de que fuera trasladado al hospital. Allí se lo mantuvo esposado a la cama y bajo constante vigilancia de dos funcionarios policiales a pesar de estar inconsciente. La atención médica fue tan deficiente que la compañera del señor Greco tuvo que hacerse cargo de prácticamente todos los cuidados personales básicos. El 4 de julio, el señor Greco falleció. Los familiares recibieron explicaciones confusas sobre las circunstancias de la muerte y el cadáver fue enterrado al día siguiente sin notificación de su familia, y sin autopsia. Ninguno de estos hechos fue debidamente investigado por la justicia provincial. ${ }^{149}$

Ante la falta de respuesta de las autoridades provinciales, la madre de la víctima presentó el 10 de septiembre de 1997 una denuncia ante la CIDH. La comisión declaró admisible el caso y se puso a disposición de las partes a fin de llegar a una solución amistosa del asunto fundada en el respeto de los derechos humanos establecidos en la misma. El diálogo

145 Véase acta del 31 de mayo de 1996, en poder del autor.

146 Véase Decreto del Poder Ejecutivo Nacional núm. 53/96, de 30 de enero de 1996, en poder del autor. En los considerandos de dicho decreto se deja sentado que el Estado federal no es el responsable interno por los hechos enunciados puesto que sucedieron en jurisdicción de la Provincia de Mendoza; no obstante lo cual corresponde dar cumplimiento a lo preceptuado en el artículo 28 inciso 1 y 2 de la convención.

147 CIDH, Informe núm. 91/03, Petición 11.804, Solución Amistosa, Juan Ángel Greco, Argentina, 22 de octubre de 2003.

148 Ibidem, párr. 8 y 11.

149 Ibidem, párr. 9 a 15. 
hacia una solución amistosa en el caso se inició en una reunión de trabajo realizada el 31 de julio de 2002, durante una visita de trabajo que la CIDH llevó a cabo en Argentina. La Provincia del Chaco hizo expresa su voluntad de comenzar este proceso. Finalmente, el acuerdo de solución amistosa fue firmado durante una reunión de trabajo realizada el 17 de octubre de 2003, durante el 1180. periodo de sesiones de la CIDH. ${ }^{150}$

El acuerdo alcanzado presenta ciertas particularidades. En primer lugar el acuerdo en este caso es firmado por las partes en el caso ante la CIDH, es decir los peticionarios y el Gobierno de la República Argentina. Agrega el acuerdo que el gobierno argentino es parte en su carácter de Estado parte de la convención americana, actuando por expreso mandato constitucional. ${ }^{151} \mathrm{La}$ Provincia del Chaco, a pesar de asumir todos los compromisos sustanciales no suscribe el acuerdo sino que lo hace el gobierno nacional "orden a lo dispuesto por el artículo 28 de la convención". No aclara el convenio si se refiere al inciso 1 o 2 del artículo 28. Las menciones a los artículos 99 y 126 de la Constitución argentina además demuestran que para las partes habría un acuerdo que sólo el gobierno nacional podría firmar acuerdos de solución amistosa en casos ante la comisión interamericana, en tanto y en cuanto implican un ejercicio de la política exterior y es una facultad delegada por las provincias al gobierno federal. En este sentido podría pensarse que sería una facultad federal y por ende cubierto bajo el inciso 1 del artículo 28. Sin embargo, dado que todos los compromisos sustantivos y el reconocimiento de responsabilidad son asumidos por la provincia parece más apropiado pensar que se está en el supuesto del inciso 2. Lamentablemente, el acuerdo guarda silencio al igual que la CIDH en su informe. En todo caso, pareciera claro que el gobierno nacional y los peticionarios tuvieron en consideración lo resuelto por la corte en el caso Garrido y Baigorria.

El compromiso llegado resalta un delicado balance entre distribución de competencias y responsabilidades internas e internacionales. Así, el primer punto del acuerdo fue el reconocimiento de responsabilidad de la responsabilidad objetiva por parte del Gobierno de la Provincia del Chaco en las circunstancias de la detención y muerte de Juan Ángel Greco. ${ }^{152}$ Agrega el acuerdo que dada la naturaleza internacional de las violaciones

150 Ibidem, párr. 5 y 7.

151 Informe núm. 91/03, párr. 16.

152 Ibidem, párr. 16 punto I.1. 
de derechos reconocidas, acontecidas en el ámbito de la jurisdicción de la Provincia del Chaco, el Gobierno de la Republica Argentina manifiesta que no tiene objeción alguna en acompañar dicho reconocimiento en el ámbito internacional en su calidad de Estado parte de la convención y de conformidad con la normativa constitucional. ${ }^{153}$

El acuerdo luego incluye las medidas de reparación tanto pecuniarias como no pecuniarias. Todas ellas fueron asumidas por la Provincia del Chaco. Al final del convenio, el Gobierno de la República Argentina y los peticionarios solicitan a la comisión interamericana que acepte los compromisos asumidos por el Gobierno de la Provincia del Chaco. ${ }^{154}$ Estos compromisos implicaron en el aspecto no económico el reexamen de la causa penal y el compromiso de instar a su reapertura de la causa penal, como del sumario administrativo y asegurar el acceso de los familiares de la víctima a las investigaciones judiciales y administrativas, a la publicación del acuerdo alcanzado y a continuar impulsando medidas legislativas y administrativas para una mejor protección de los derechos humanos. En el aspecto económico el Gobierno de la Provincia del Chaco se compromete a reparar económicamente a los familiares de Juan Ángel Greco. ${ }^{155}$

La comisión en un escueto párrafo consideró que este acuerdo era compatible con la convención americana. No se expresó la comisión sobre el hecho que todos los compromisos fuesen asumidos por la provincia y no por el Estado nacional. Tampoco, la comisión, a diferencia del caso Guardatti, agradeció a las autoridades de la Provincia del Chaco por su participación y acciones en el acuerdo alcanzado. ${ }^{156}$

Estas soluciones amistosas, fueron exitosas en cuanto lograron solucionar parte sustancial del problema denunciado involucrando activamente a la provincia respectiva en todo el procedimiento. Pero esta situación fue una solución ad hoc que no cuenta con un respaldo institucional donde puedan coordinarse de manera permanente el gobierno nacional y los provinciales para responder a denuncias internacionales, para buscar soluciones en caso de ser posible, para articular posiciones comunes, para dar cumplimiento a decisiones de organismos internacionales. Especialmente debe tenerse en cuenta que múltiples casos se hallan pendien- 
tes ante la comisión interamericana que involucran las acciones u omisiones de las autoridades provinciales y que aún no han logrado solucionarse. En parte precisamente por esta carencia de un mecanismo efectivo que provea un marco de acción.

\section{REFLEXIONES FINALES}

La libertad y soberanía de los Estados para adoptar la forma federal, unitaria o aquella que estimen pertinente, no puede retardar injustificadamente la implementación de la convención americana o violarla de cualquier otra forma amparándose en su forma federal de gobierno. Los principios generales del derecho internacional relativos a la responsabilidad internacional de Estados federales así como su aplicación peculiar en el ámbito de los derechos humanos, atribuyen la responsabilidad por las acciones $\mathrm{y} / \mathrm{u}$ omisiones de sus subdivisiones políticas a los gobiernos centrales. Estos últimos no pueden eximirse de dicha responsabilidad alegando que sus poderes constitucionales de control sobre las provincias son insuficientes para exigir el cumplimiento de las obligaciones internacionales.

El artículo 28 de la convención americana refleja estos principios generales del derecho internacional, aplicados específicamente a los Estados federales en el contexto del derecho internacional de los derechos humanos. El artículo 28 tiene por objeto clarificar, precisar y hacer más determinante, inmediata y directa la exigencia del cumplimiento de la obligación de respetar y garantizar los derechos y libertades en el marco de los Estados federales. El artículo 28 no altera o disminuye el alcance de los artículos 1 y 2 de la convención sino que los complementa. Una interpretación distinta, carecería de sentido al privar de efecto útil a la convención en las unidades componentes de los Estados federales.

Los principios generales del derecho internacional, la interpretación teleológica, literal y contextual de la convención americana así como la jurisprudencia de la corte suprema permiten sostener que en este campo tanto el gobierno nacional como los gobiernos locales se encuentran en la obligación de asegurar la plena vigencia de los derechos contenidos en la convención y en los tratados internacionales en general. En este sentido, creemos que el argumento de la estructura federal para justificar el incumplimiento de las obligaciones internacionales o en su caso para pretender desentenderse de las mismas no es otra cosa que una defensa 
política que en definitiva demuestra que el gobierno nacional no desea utilizar todas las facultades jurídicas que se tienen para lograr que las unidades de la Federación den estricto cumplimiento a las normas de derechos humanos. ${ }^{157}$

Desde esta perspectiva resulta imperativo que en Argentina así como en cualquier Estado federal, se desarrolle un mecanismo efectivo para asegurar que tanto el gobierno federal como los gobiernos provinciales se hallan en condiciones de garantizar la vigencia de los derechos reconocidos internacionalmente. Los principios del derecho internacional, la interpretación de las normas convencionales, la jurisprudencia de la propia Corte Suprema, y en particular la realidad en las provincias, demuestra la necesidad de que se avance de la situación actual en la que el gobierno federal es en muchos aspectos simplemente reactivo ante denuncias internacionales. Debería crearse un mecanismo donde se incorpore de una manera constructiva a las provincias para permitir la interacción entre una y otra esfera de gobierno. El objetivo debería ser facilitar y hacer posible la internalización de las obligaciones internacionales por parte de las provincias.

Las múltiples y variadas cargas que pesan tanto sobre el gobierno nacional como sobre los provinciales requieren de un mecanismo de diálogo, de coordinación, de creación de consensos entre todos los actores, nacionales y provinciales, involucrados para hacer efectivo el ejercicio de los derechos reconocidos internacionalmente en todo el ámbito territorial del país. Este mecanismo debe permitir la búsqueda de soluciones mediante un justo equilibrio entre el respeto a las autonomías provinciales y el cumplimiento de las obligaciones emergentes de los tratados de derechos humanos. Debe facilitar la conciliación de los distintos intereses en juego y particularmente debe tener como meta esencial el asegurar de la mejor manera la plena vigencia de los derechos reconocidos en los instrumentos internacionales para todos los habitantes independientemente de la provincia donde se encuentren.

Hasta ahora, el Consejo Federal de Derechos Humanos que existe en el ámbito del Ministerio de Justicia y Derechos Humanos no ha logrado cumplir este objetivo. Este consejo federal, se compone de representantes

157 Véase en el mismo sentido para el caso de Australia: Joseph, Sarah, "Federalism and Human Rights", International Legal Challenges for the Twenty-first Century, Proceedings of a Joint Meeting of the Australian \& New Zealand Society of International Law and the American Society of International Law, 26-29 June 2000, p. 331. 
de las provincias y del gobierno nacional y es coordinado por la Secretaría de Derechos Humanos.

De lo que se trata es de asegurar que el piso mínimo de los derechos sea el contenido en el derecho internacional de los derechos humanos. Cada provincia puede elegir los medios, formas, políticas, planes, programas que estime pertinente y que refleje sus particularidades, historia, tradiciones, idiosincrasia. En este sentido, el mecanismo propuesto podrá servir también de marco de intercambio de las experiencias exitosas entre las distintas provincias. La experiencia argentina y comparada demuestra que muchas veces las unidades federativas desarrollan mejores mecanismos de protección que a nivel federal.

Dado que la implementación de las obligaciones internacionales de derechos humanos es una tarea permanente, el mecanismo también deberá ser permanente. Principalmente este mecanismo debe ser activo y propositito y no reactivo. Por ejemplo debería servir de foro para la revisión de la legislación provincial en áreas críticas como pueden ser la penal o procesal penal, o análisis de políticas públicas como seguridad ciudadana o formación de los agentes encargados de hacer cumplir la ley. Todo ello para asegurar que se cumplan con las normas internacionales. Este mecanismo también debería estar involucrado en la preparación de informes que deben presentarse ante los distintos órganos internacionales de monitoreo y en particular debe servir de foro para estudiar las recomendaciones que se le formulen al país para asegurar que las mismas son implementadas en todas las provincias. Asimismo debería permitir el análisis de las decisiones en casos individuales con un doble objetivo. Facilitar la coordinación para el cumplimiento de las mismas entre el gobierno nacional y la provincia que pudiese estar implicada. Al mismo tiempo y por el carácter proactivo que consideramos debe tener, el análisis de las decisiones debería estar destinado a identificar las prácticas, políticas, acciones u omisiones, legislación que haya sido considerada por el respectivo organismo internacional como violatoria de alguna norma internacional a fin de asegurar que tal situación no existe en el resto de las provincias y en el caso de que si exista eliminar o modificar dicha práctica, políticas, legislación como ejercicio del deber de prevención contenido en los tratados de derechos humanos.

La corte interamericana, como parte de las reparaciones por violaciones a derechos humanos ha ordenado la definición de políticas de Estado de corto, mediano y largo plazo en materia de que se trate que sea plena- 
mente consistente con los compromisos internacionales del Estado en cuestión. ${ }^{158}$ Esto es precisamente lo que nosotros planteamos que se requiere en un país con estructura federal como Argentina, la definición de una política de Estado de corto, mediano y largo plazo en materia de derechos humanos para asegurar que el gobierno nacional y los provinciales están en condiciones de respetar y garantizar efectivamente las libertades públicas reconocidas internacionalmente. Y el mecanismo que proponemos debe ser el espacio para el diálogo y la definición de estas políticas públicas.

Finalmente, el mecanismo debe prever las soluciones ante potenciales desacuerdos entre el gobierno nacional y los provinciales. Dado que el Estado federal será en definitiva responsable internacionalmente, al menos en materia de casos individuales su opinión debería prevalecer y deberían especificarse claramente los mecanismos legales para efectivizarla. Sin pretender ser exhaustivos algunas propuestas que pueden analizarse serían las siguientes. En materia de reparaciones económicas, el gobierno nacional debería estar facultado para pagar las indemnizaciones correspondientes y luego repetirlas contra la provincia respectiva o retenerla de la coparticipación federal correspondiente. En el aspecto investigativo y de justicia, dada la naturaleza federal de todo lo relativo a tratados internacionales, según lo señalado por la corte suprema, podría pensarse en la transferencia de las causas respectivas a la justicia federal. ${ }^{159}$ En materia de reformas legislativas la situación puede ser más compleja pero ya la corte suprema ha dada algunas pautas. Verbitsky puso en claro que la legislación nacional puede servir de ley marco o piso mínimo para las legislaciones provinciales. Por ejemplo ya existe el precedente de la ley núm. 23.098 sobre procedimiento de habeas corpus, que dispone: "El capítulo primero tendrá vigencia en todo el territorio de la nación, cualquiera sea el tribunal que la aplique. Sin embargo, ello no obstará a la aplicación de las constituciones de provincia o de leyes dictadas en su consecuencia, cuando se considere que las mismas otorgan más eficiente protección de los derechos a que se refiere esta ley".

Una alternativa diferente, sería otorgar al gobierno nacional legitimación activa y crear una causa de acción ante la corte suprema para solici-

158 Corte IDH. Caso "Instituto de Reeducación del Menor" vs. Paraguay. Sentencia de 2 de septiembre de 2004. Serie C No. 112, párr. 316.

159 Tal como lo hace la reciente reforma constitucional brasilera o lo propone la reforma constitucional planteada en México. Véase notas.... Y texto que acompaña. 
tar la declaración de inconstitucionalidad de la norma provincial por ser contraria al tratado respectivo. Otra posibilidad sería explorar el precedente constitucional venezolano que permite al defensor del pueblo presentar ante los órganos legislativos nacionales, estadales o municipales, proyectos de ley u otras iniciativas para la protección progresiva de los derechos humanos. ${ }^{160}$

Para concluir, el federalismo no es un problema sino una posibilidad. Al crear un doble sistema de garantías constitucionales, los derechos teóricamente tienen mejores posibilidades de ser protegidos. El derecho internacional de los derechos humanos provee un tercer sistema de protección. Por lo tanto de lo que se trata es de buscar la manera de integrar a los tres sistemas plenamente. Y para ello se requiere de voluntad política y no de excusas jurídicas. 